\title{
Zerumbone ameliorates behavioral impairments and neuropathology in transgenic APP/PS1 mice by suppressing MAPK signaling
}

Lei Li

Nanjing Medical University

Xiang-Hui Wu

Nanjing Medical University

Xiao-Jing Zhao

Nanjing Medical University

Lu Xu

Nanjing Medical University

Cai-Long Pan

Nanjing Medical University

Zhi-Yuan Zhang ( $\nabla$ zzy@njmu.edu.cn )

Nanjing Medical University

\section{Research}

Keywords: Alzheimer's disease, APP/PS1 transgenic mouse, zerumbone, cerebral amyloidosis, neuroinflammation, MAPK signaling pathway

Posted Date: November 11th, 2019

DOI: https://doi.org/10.21203/rs.2.17060/v1

License: (c) (i) This work is licensed under a Creative Commons Attribution 4.0 International License. Read Full License 


\section{Abstract}

Background: Alzheimer's disease (AD) is a major clinical problem, but there is a distinct lack of effective therapeutic drugs for this disease. We investigated the potential therapeutic effects of zerumbone, a subtropical ginger sesquiterpene, in transgenic APP/PS1 mice, rodent models of AD which exhibit cerebral amyloidosis and neuroinflammation.

Methods: The N9 microglial cell line and primary microglial cells were cultured to investigate the effects of zerumbone on microglia. APP/PS1 mice were treated with zerumbone, and non-cognitive and cognitive behavioral impairments were assessed and compared between the treatment and control groups. The animals were then sacrificed, and tissues were collected for further analysis. The potential therapeutic mechanism of zerumbone and the signaling pathways involved were also investigated.

Results: Zerumbone suppressed the expression of pro-inflammatory cytokines and induced a switch in microglial phenotype from the classic inflammatory phenotype to the alternative anti-inflammatory phenotype by inhibiting the mitogen-activated protein kinase (MAPK)/nuclear factor-kappa B signaling pathway in vitro. After a treatment period of 20 days, zerumbone significantly ameliorated deficits in both non-cognitive and cognitive behaviors in transgenic APP/PS1 mice. Zerumbone significantly reduced $\beta-$ amyloid deposition and attenuated pro-inflammatory microglial activation in the cortex and hippocampus. Interestingly, zerumbone significantly increased the proportion of anti-inflammatory microglia among all activated microglia, potentially contributing to reduced $\beta$-amyloid deposition by enhancing phagocytosis. Meanwhile, zerumbone also reduced the expression of key molecules of the MAPK pathway, such as p38 and extracellular signal-regulated kinase.

Conclusions: Overall, zerumbone effectively ameliorated behavioral impairments, attenuated neuroinflammation, and reduced $\beta$-amyloid deposition in transgenic APP/PS1 mice. Zerumbone exhibited substantial anti-inflammatory activity in microglial cells and induced a phenotypic switch in microglia from the pro-inflammatory phenotype to the anti-inflammatory phenotype by inhibiting the MAPK signaling pathway, which may play an important role in its neuroprotective effects. Our results suggest that zerumbone is a potential therapeutic agent for human neuroinflammatory and neurodegenerative diseases, in particular AD.

\section{Background}

Alzheimer's disease (AD) is the major cause of dementia and the most common form of neurodegeneration. The clinical hallmarks of this disease include functional, cognitive, and behavioral manifestations and deficits in non-cognitive behaviors. Furthermore, the development of senile plaques composed of extracellular accumulated $\beta$-amyloid $(A \beta)$ peptides ${ }^{[1]}$ is one of the most distinct neuropathological features of $A D$. It is hypothesized that $A \beta$ peptides are toxic and contribute to memory loss, behavioral impairments, and further neurodegenerative pathology in $A D^{[2,3]}$. In addition to $A \beta$ aggregation, neuroinflammation also plays a pivotal role in the pathophysiology of $A D^{[4]}$. 
Neuroinflammation is characterized by microglial and astroglial activation, and the release of numerous inflammatory mediators, particularly around amyloid plaques ${ }^{[5,6]}$. In $A D$, excessive production and inefficient clearance of $A \beta$ lead to $A \beta$ aggregation and trigger a pro-inflammatory response, which contributes to cell death and neural dysfunction ${ }^{[7]}$. This chronic neuroinflammation promotes $A \beta$ liberation during amyloid precursor protein (APP) processing ${ }^{[8]}$. All of the aforementioned neuropathological changes establish a deleterious self-perpetuating vicious cycle which promotes the pathogenesis of $A D{ }^{[9]}$. Therefore, controlling neuroinflammation and reducing $A \beta$ accumulation in the $A D$ brain are thought to be promising approaches for the treatment of $A D^{[9]}$.

Microglia are the resident phagocytes of the central nervous system (CNS), and their phagocytic capacity can be regulated to enhance the clearance of $A \beta^{[10,11]}$. This suggests that reversing microglial phenotype from the disease state to the cognitively-normal phenotype or specifically activating microglia could be effective therapeutic approaches for $A D{ }^{[12,13]}$. In a recent study, deferoxamine treatment switched the microglial phenotype from the classic to the alternative phenotype, thereby decreasing $A \beta_{42}$ deposition and ameliorating cognitive impairments in APP/PS1 mice ${ }^{[14]}$. It's also reported that gamma oscillations induced a distinct microglial phenotype, and thereby promoted the microglial phagocytosis of $A \beta$ in $5 \times F A D$ mice ${ }^{[15]}$. The classically activated (M1, pro-inflammatory) and alternatively activated (M2, antiinflammatory) phenotypes are two different microglial polarization states ${ }^{[16]}$. Alternatively activated (M2) microglia have been reported to possess a significantly increased phagocytic capacity for $A \beta$ compared to classically activated (M1) microglia ${ }^{[17]}$. Classically activated (M1) microglia are characterized by an increased production of pro-inflammatory mediators, including tumor necrosis factor-a (TNF-a), interleukin-1 $\beta(\mathrm{IL}-1 \beta)$, and interleukin-6 $(\mathrm{IL}-6)^{[18]}$. These cells exacerbate neuronal damage and impede cellular repair in several neurodegenerative diseases ${ }^{[19]}$. Conversely, alternatively activated M2 microglia are known to up-regulate anti-inflammatory mediators, such as arginase-1 (Arg-1), CD206, and interleukin-10 (IL-10) ${ }^{[20]}$. These cells exert neuroprotection and promote neuronal recovery and remodeling ${ }^{[21]}$. Therefore, understanding how to control neuroinflammation and enhance microglial phagocytosis is key for the development of novel AD treatments.

The mitogen-activated protein kinase (MAPK) signaling pathway mediates fundamental cellular and biological processes related to immune responses. This pathway consists of three major classes of MAPKs, namely extracellular signal-regulated kinase (ERK), C-Jun N-terminal kinase (JNK), and p38 22,23$]$. Impaired and uncontrolled regulation of the MAPK pathway has been implicated in a number of immunological disorders including microglia dysfunction and neuroinflammation ${ }^{[24]}$, suggesting its involvement in CNS disorders. Previous studies have revealed that the MAPK signaling pathway plays an important role in $A D$ pathogenesis activation of this pathway was observed in $A D$ brains and pathologically-similar brains ${ }^{[25,26]}$. ERK and p38 were observed to be closely associated with AD pathology, especially with $A \beta$ accumulation in microglia responded strongly to $\beta$-amyloid ${ }^{[24]}$. Inhibition of MAPK signaling reverses memory impairments in mouse models of $A D^{[27,28]}$ and is reported to promote microglial anti-inflammatory (M2) polarization and thereby inhibit neuroinflammation ${ }^{[29,30]}$. Taken 
together, improving microglial function via the regulation of MAPK signaling may be a promising strategy for the treatment of $A D$.

Zerumbone (2,6,9,9-tetramethyl-2E,6E,10E-cycloundeca-2,6,10-trien-1-one) is a sesquiterpenoid compound extracted from the rhizomes of Zingiber zerumbet Smith, a wild ginger which primarily grows in Southeast Asia ${ }^{[31-33]}$. In traditional Asian medicine, the rhizome of this plant is considered to have antirheumatic, antispasmodic, carminative, and analgesic effects ${ }^{[34]}$. Indeed, recent studies have indicated that zerumbone has several pharmacological effects, namely anti-cancer, chemo-preventive, and anti-inflammatory effects ${ }^{[32]}$. Zerumbone has been shown to reduce the expression of inflammatory cytokines and molecules in different inflammatory-induced cell cultures ${ }^{[35,36]}$. For example, zerumbone suppressed nuclear factor-kappa B (NF-kB), inducible nitric oxide synthase (iNOS), and TNF-a expression, reduced malondialdehyde accumulation, and increased glutathione and glutathione reductase levels in mice with UVB-induced photokeratitis ${ }^{[37]}$. In a mouse model of neuropathic pain, zerumbone exhibited antiallodynic and antihyperalgesic activities via the suppression of IL-1 $1 \beta$, IL-6, and TNF-a ${ }^{[38]}$. Notably, the inhibition of these pro-inflammatory markers by zerumbone is accompanied by the attenuation of the MAPK signaling pathway in lipopolysaccharide (LPS)-induced macrophages ${ }^{[35]}$. Moreover, several other sesquiterpenoids have been suggested to possess anti-neuroinflammatory activity or control $A \beta$

production in the brain, identifying them as potential therapeutic agents for $A D{ }^{[39,40]}$. However, the effect of zerumbone on neurodegenerative disorders, especially $A D$, is currently unknown.

Hence, a transgenic mouse model (C57BL/6J genetic background) co-expressing mutated human APP and presenilin 1-21 (PS1-21) (APP/PS1-21 mice) was used in our in vivo study. These mice exhibit aggressive AD pathology, specifically neuroinflammation and impairments in behavioral/cognitive functions ${ }^{[41,42]}$. We used a murine $\mathrm{N} 9$ microglial cell line and primary microglia from mouse brains to study the therapeutic potential of zerumbone for $A D$ in vitro, and to explore the potential effects of zerumbone on MAPK signaling. Our results may facilitate the development of novel therapeutic approaches for the treatment of $A D$.

\section{Methods}

\section{Animals}

Male APP/PS1-21 mice on a C57BL/6J background were obtained from Prof. M. Jucker (University of Tuebingen, Germany). Heterozygous male APP/PS1-21 mice were bred with wild-type C57BL/6J females (Charles River Germany, Sulzfeld, Germany). Offspring were tail-snipped and genotyped using PCR with primers specific for the APP-sequence (forward, "GAATTCCGACATGACTCAGG”; reverse, "GTTCTGCTGCATCTTGGACA"). Animals were housed under a 12-hour light/ dark cycle with free access to food and water. All experiments and protocols were licensed and approved by the local government in Germany, according to The German Animal Welfare Act (TierSchG) of 2006; or by Nanjing Medical University Animal Care and Use Committee in accordance with the regulations of the ethics committee of 
the International Association for the Study of Pain and the Guide for the Care and Use of Laboratory Animals (The Ministry of Science and Technology of China, 2006) in China.

\section{Reagents}

DMEM/F-12 medium, fetal bovine serum (FBS), penicillin, and streptomycin were purchased from Gibco (Waltham, MA, USA). The $A \beta$ used in these experiments was human $A \beta_{1-42}$ (ChinaPeptides, Shanghai, China). The $A \beta$ powder was dissolved and incubated in DMSO, and was then diluted to a stock solution $(500 \mu \mathrm{M})$ with phosphate buffered saline (PBS; Boster Biological Technology, Wuhan, China). Before the experiments, we incubated the mixed stock solution at $37^{\circ} \mathrm{C}$ for 24 hours. Zerumbone (Zer, $>98 \%$ of Purity, Fig. 1) and lipopolysaccharide (LPS) were purchased from Sigma-Aldrich (Munich, Germany). Zerumbone was dissolved in DMSO to produce a $20 \mu \mathrm{M}$ stock solution. Same volume or amount of DMSO and/or PBS was applied as vehicles. For the in vitro experiments, stock solutions of $A \beta$ or zerumbone were further diluted to different working concentrations with culture media. After 6 hours of pretreatment of Zer or vehicle, we treated the cells with the $10 u M A \beta_{1-42}$ for 12 hours.

\section{Cell culture}

Primary microglia were isolated from the cortex of newborn (postnatal day $0-2$ ) C57BL/6J mice by mild trypsinization as previously described ${ }^{[43]}$. Briefly, the cortex was chopped and digested into a single cell suspension which was incubated in DMEM/F-12 containing 10\% FBS and $100 \mathrm{U} / \mathrm{ml} 1 \%$ penicillin/streptomycin. After 15 days of incubation, mixed glial cells were shaken for two hours at $37^{\circ} \mathrm{C}$. Detached microglia were then harvested for the subsequent experiments. In some experiments, primary microglia were also isolated from brain homogenates as previously described with minor modifications ${ }^{[44]}$. Briefly, the brains of zerumbone-treated or control mice were minced and finely homogenized in ice-cold Hank's Balanced Salt Solution (HBSS, pH 7.4). The homogenates were centrifuged twice at $250 \mathrm{~g}$ for 5 minutes. The pellet was re-suspended in $1 \mathrm{ml} 70 \%$ isotonic Percoll (GE Healthcare, Uppsala, Sweden). A discontinuous Percoll density gradient was layered as follows: $70 \%$, $50 \%$, and $35 \%$ isotonic Percoll, and PBS. The gradient was centrifuged at $1200 \mathrm{~g}$ for 45 minutes at $4{ }^{\circ} \mathrm{C}$, and microglia were collected from the $70 / 50 \%$ interphase Percoll layers.

Isolated cells were washed and re-suspended in sterile HBSS, and were then stained with PE-conjugated anti-CD11b and FITC-conjugated anti-CD45 antibodies (1:1000, Serotec, Oxford, UK). The purity of $\mathrm{CD} 11 \mathrm{~b}^{+} / \mathrm{CD} 45^{\text {low }}$ microglia was confirmed to be $>85 \%$. The primary microglia were grown in DMEM medium at $37^{\circ} \mathrm{C}$ and $5 \% \mathrm{CO}_{2}$. All cultures were supplemented with penicillin/streptomycin $(100 \mathrm{U} / \mathrm{ml})$ and $10 \%$ FBS. Subsequently, $10^{5}$ cells were seeded onto 12 -well cell culture plates and cultured.

\section{Cell viability assays}


Cell viability was evaluated using a Cell Counting Kit-8 (CCK-8; Yeasen, Shanghai, China). Briefly, after each treatment, $10 \mu \mathrm{l}$ of CCK-8 reagent was added and microglia were incubated for 4 hours at $37^{\circ} \mathrm{C}$ and $5 \% \mathrm{CO}_{2}$. The absorbance of the samples was measured at $450 \mathrm{~nm}$ using a microplate reader. Cell viability was determined using the following calculation: cell viability $(\%)=(A$ (stimulated $)-A$ (blank) / $(A$ (control) $-\mathrm{A}($ blank $) \times 100 \%$.

\section{RNA isolation and real-time PCR}

To determine the effects of zerumbone on the inflammatory response of microglia in vitro, N9 microglial cells and primary microglial cells were used. As previously mentioned, all cells were cultured in DMEM medium with $100 \mathrm{U} / \mathrm{ml}$ penicillin/streptomycin and 10\% FBS. The cells were seeded in 12-well plates, and were then divided into three groups. Cells in the vehicle group were treated with a solution of $A \beta_{1-42}$. Cells in the $A \beta$ group were treated with $10 \mu \mathrm{M} \mathrm{A} \beta_{1-42}$ for 24 hours. Cells in the Zer group were pre-treated with zerumbone (at concentrations of 1,3 , or $10 \mu \mathrm{g} / \mathrm{ml}$ ) for 24 hours before treatment.

Total RNA was extracted from cells using the RNeasy Mini Kit (QIAGEN, Hilden, Germany) following the manufacturer's protocol. The QuantiTect Reverse Transcription Kit (QIAGEN) was used to reverse transcribe RNA $(1 \mu \mathrm{g})$ into cDNA. Real-time PCR analysis was performed using ChamQ SYBR qPCR Master Mix (Vazyme, Nanjing, China) to measure the mRNA expression of IL-1 $\beta$, IL-6, iNOS, TNF- $a$, CD206, IL-10, and ARG-1. The primers used are shown in Table 1. The amplification efficiency of these primers had previously been established using calibration curves. Each $20 \mu \mathrm{l}$ qPCR reaction mixture contained $3 \mu \mathrm{l}$ water, $1 \mu \mathrm{l}$ forward primer $(20 \mu \mathrm{mol} / \mathrm{l}), 1 \mu \mathrm{l}$ reverse primer $(20 \mu \mathrm{mol} / \mathrm{l}), 10 \mu \mathrm{l}$ MasterMix, and $50 \mathrm{ng}$ cDNA. PCR amplification was conducted as follows: denaturation at $95^{\circ} \mathrm{C}$ for 10 minutes, 40 cycles of $95^{\circ} \mathrm{C}$ for 10 seconds and $65^{\circ} \mathrm{C}$ for 60 seconds, followed by 1 cycle at $97^{\circ} \mathrm{C}$ for 1 second. Finally, a melting step was performed consisting of 10 seconds at $95^{\circ} \mathrm{C}, 60$ seconds at $65^{\circ} \mathrm{C}$, and slow heating at a rate of $0.1^{\circ} \mathrm{C}$ per second to $97^{\circ} \mathrm{C}$ with continuous fluorescence measurement. Quantification was performed using the comparative CQ method $\left(2^{-\triangle \Delta C Q}\right)$. The expression of each target mRNA was calculated relative to that of $\beta$-actin (four samples from each group were analyzed by PCR) ${ }^{[45,46]}$.

\section{Nitric oxide detection and enzyme-linked immunosorbent assay}

Supernatants from different wells were collected and a standard Griess assay (Sigma-Aldrich) was performed to analyze the production of nitric oxide (NO). Enzyme-linked immunosorbent assay (ELISA) kits for IL-1 $\beta$ (Thermo Scientific, Waltham, MA, USA), TNF- $a$, IL-10, and prostaglandin E2 (PGE2; BioLegend Inc., San Diego, CA, USA) were used to detect the concentrations of these cytokines in microglial culture supernatants. To further confirm the role of the MAPK pathway in the effects of zerumbone, microglia were pre-treated for 2 hours with $1 \mu \mathrm{M}$ U0126 (an ERK inhibitor), SB202190 (a p38 inhibitor), or BAY 11-7082 (a NF-kB inhibitor), and further cultured with $3 \mu \mathrm{g} / \mathrm{ml}$ zerumbone. ELISAs were 


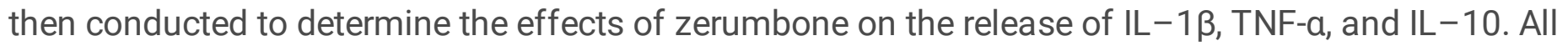
samples were analyzed four times.

\section{Flow cytometry analysis}

To detect the effects of zerumbone on $A \beta$ phagocytosis, microglia were stimulated with $A \beta_{1-42}$ and incubated with or without zerumbone $(3 \mu \mathrm{g} / \mathrm{ml})$ for 24 hours. Each tube of cells was incubated with $1 \mu \mathrm{l}$ $(500 \mathrm{ng} / \mu \mathrm{L}) \mathrm{A} \beta_{1-42}$ (HiLyte ${ }^{\mathrm{TM}}$ Fluor 488-labeled, Eurogentec, Liege, Belgium) for 1 hour at $4{ }^{\circ} \mathrm{C}$. Data were analyzed using FlowJo Software (Version 7.6.1; TreeStar, Ashland, OR, USA).

\section{Western blot analysis}

To identify the signaling pathway involved in the effects of zerumbone, total proteinwas extracted from primary microglia and the brains of vehicle- and zerumbone-treated APP/PS1 mice using RIPA lysis buffer (50 mM Tris, $150 \mathrm{mM} \mathrm{NaCl}, 1 \%$ TritonX-100, 1\% sodium deoxycholate, and 1\% SDS). The volumes and contents of all samples were equalized with RIPA lysis buffer, and the samples were electrophoretically separated on $12 \%$ SDS-PAGE gels. Following this, the proteins were transferred to PVDF membranes (Millipore, Billerica, MA, USA) using Trans-Blot apparatus (Bio-Rad, Hercules, CA, USA). The membranes were blocked with Tris-buffered saline solution (TBS) containing $5 \%$ bovine serum albumin (BSA) for 2 hours, and were then incubated at $4{ }^{\circ} \mathrm{C}$ overnight with primary antibodies against cyclooxygenase-2 (Cox-2), microsomal prostaglandin E synthase-1 (m-PGES-1), ERK, p38 MAPK, NFKB p65 (1:1000, Abcam, Cambridge, MA, USA), and $\beta$-actin (1:500, Sigma, St. Louis, MO, USA). The proteins were visualized using appropriate horseradish peroxidase-conjugated secondary antibodies and an enhanced chemiluminescence reagent. The signals of specific proteins were detected using a Gel Doc imager (Bio-Rad), and were expressed as a fraction of the signal of the control protein ${ }^{[47,48]}$.

\section{Mouse treatment and groups}

In order to be administered orally, zerumbone was suspended in $1 \%$ carboxymethylcellulose (CMC, Blanose $\AA$, Hercules-Aqualon, Düsseldorf, Germany) at a concentration of $3.5 \mathrm{mg} / \mathrm{ml}$ (zerumbone/CMC solution). Five-month-old mice were divided into two groups. Group 1 comprised seven APP/PS1-21 mice (five males and two females) which were treated for 20 days with zerumbone $(25 \mathrm{mg} / \mathrm{kg}$ by daily gavage). Group 2 comprised seven sex- and age-matched APP/PS1-21 mice which were administered the same volume $(200 \mu \mathrm{l})$ of $1 \% \mathrm{CMC}$ dissolved in water.

\section{Design and evaluation of nest construction assay}


A nest construction assay ${ }^{[49]}$ was modified to identify deficits in the affiliative/social behavior of APP/PS1 mice and potential changes following treatment.

For at least 24 hours, mice were individually housed in clean plastic cages with wood chip bedding (approximately $1 \mathrm{~cm}$ deep) lining the floor. Identification cards were coded to render the experimenter blind to the sex, age, and genotype of the mice. Two hours prior to the onset of the dark phase of the light/dark cycle, a $20 \times 20 \mathrm{~cm}$ piece of paper towel torn into approximately $5 \times 5 \mathrm{~cm}$ square pieces was placed in each cage. Mice were tested in balanced groups of mixed genotypes to reduce variability in housing conditions. The next morning (approximately 16 hours later), the cages were inspected for nest construction. Pictures were taken prior to evaluation for documentation. Paper towel nest construction was scored using a 3-point system: $1=$ no biting or tears on the paper, $2=$ moderate biting and/or tears on the paper but no coherent nest (not grouped into a corner of the cage), and $3=$ the vast majority of paper torn into pieces and grouped into a corner of the cage $\mathrm{e}^{[49,50]}$.

\section{Social interaction: resident-intruder assay}

The social interaction assay was performed according to previous studies ${ }^{[50,51]}$ with minor modifications. The resident-intruder assay was video-recorded to evaluate all distinct behaviors of vehicle-treated and zerumbone-treated WT or AD mice (residents) in the presence and absence of an intruder mouse, and to analyze the movement of the mice to assess their overall activity level and overt neurobiological differences. In this assay, the observer was blinded to treatment allocation. A mouse was placed in a clean plastic cage identical to its home cage $(325 \mathrm{~mm} \times 210 \mathrm{~mm} \times 185 \mathrm{~mm})$ for 15 minutes to establish it as the "resident" mouse. An age-, weight-, and sex-matched untreated naive mouse (the "intruder mouse") was then introduced for a second 15-minute period.

The numbers of independent (15 minutes without intruder and 15 minutes with intruder) and interactive behavioral events (15 minutes with intruder) were counted for the resident mouse. Independent behavioral events included sniffing the environment, rearing alongside the cage, rearing independently, digging, circling clockwise, circling counter-clockwise, allogrooming, freezing, and scratching. Interactive behavioral events included sniffing the other mouse, following, grooming, rearing at the other mouse, sitting or lying next to the other mouse, backing or running away from the other mouse, biting, boxing or wrestling, mounting, pinning, and tail-rattling. The recorded videos were analyzed, and the numbers of events were counted by three independent observers blinded to treatment allocation.

To calculate the total distance traveled and quantify all identifiable distinct behaviors, both 15-minute sessions were videotaped at a frame rate of $15 \mathrm{~Hz}$. This sampling rate ensured that fast movements of the mice were sufficiently captured and allowed for a fine-grained analysis of the trajectory of these movements, but maintained manageable file sizes. A region of interest in the captured video $(500 \times 310$ pixels) was saved directly to a computer for later analysis. 
Following acquisition of the video, the position of the mouse was localized in each frame. Tracking was performed using Java-based software (Oracle, Redwood City, CA, USA) ${ }^{[52]}$. To determine the location of the mouse in each frame, the pixel of maximum intensity was identified, and a subset image around this pixel was extracted. The center of intensity of the subset image was calculated and used to determine the object's $\mathrm{X}$ and $\mathrm{Y}$ locations. The total distance traveled per transgenic mouse was then calculated using mouse behavior analysis software developed in our lab.

\section{Novel object recognition test}

In the training phase of the novel object recognition test, each mouse was placed into the experimental arena with two identical green objects $(5 \times 5 \times 5 \mathrm{~cm})$ and allowed to explore for 10 minutes. Twenty-four hours later, the novel object preference test (10 minutes) was conducted. The mouse was placed in the arena and presented with two objects in the same position as before, one familiar object and one novel red plastic object $(3.5 \times 4 \times 6 \mathrm{~cm})$. The length of time that the animal spent exploring the novel object was recorded. The recognition index (RI) was determined using the following calculation: recognition index $=$ the length of time spent exploring the novel object/the total length of time spent exploring both objects $\times 100$.

\section{Morris water maze test}

The Morris water maze (MWM) test was conducted in a circular tank $(120 \mathrm{~cm}$ diameter, $60 \mathrm{~cm}$ height). The depth of the water was $0.3 \mathrm{~m}$, and the temperature of the water was $23-25^{\circ} \mathrm{C}$. A platform $(7.5 \mathrm{~cm}$ diameter) was placed in one quadrant of the pool, $13 \mathrm{~cm}$ from the edge. After one day of habitation, training was initiated, and each mouse underwent three 1-minute trials per day. After 4 days of training, the probe test was then conducted. The escape latency of each mouse, defined as the time taken to find the hidden platform, was recorded and analyzed.

\section{Immunohistochemistry and image analysis}

Zerumbone- and vehicle-treated mice were sacrificed after 20 days of treatment. The mice were deeply anesthetized with ether and perfused intracardially with ice-cold $4 \%$ paraformaldehyde in PBS. The brains were quickly removed and post-fixed in $4 \%$ paraformaldehyde overnight at $4{ }^{\circ} \mathrm{C}$. The post-fixed brains were cut into two hemispheres. Both hemispheres were embedded in paraffin, serially sectioned (3- $\mu \mathrm{m}$ thickness), and mounted on silane-covered slides. These sections were then stained via immunohistochemistry as described previously ${ }^{[53]}$. The following antibodies were used: anti-A $\beta$ (1:100, Abcam) for $A \beta$ deposition, anti-ionized calcium binding adaptor molecule-1 (Iba-1; 1:200, Wako, Neuss, Germany) for activated microglia, and anti-CD206 (1:100, Biorbyt, Cambridge, UK) for M2 microglia. The rabbit polyclonal anti-A $\beta$ antibody (ab2539) was generated against the synthetic peptide 
DAEFRHDSGYEVHH conjugated to Keyhole Limpet Hemocyanin (KLH), corresponding to amino acids 114 of human $A \beta$.

CD206, widely known as the mannose receptor, is expressed by many types of cell, including macrophages and various epithelial cells. CD206 is expressed by microglia with an anti-inflammatory phenotype, but not by those with a pro-inflammatory phenotype, and is therefore used as an marker of anti-inflammatory microglia ${ }^{[54]}$. A double-staining experiment with anti-lba-1 and anti-CD206 antibodies was performed. After the brain tissue sections were immune-labeled with Iba- 1 as previously described, they were once more irradiated and incubated with the primary anti-CD206 antibody for 2 hours at $20^{\circ} \mathrm{C}$.

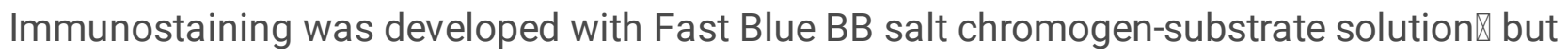
counterstaining with hemalum was not performed.

After immunostaining, the hemisphere sections were examined using a light microscope (Nikon Coolscope; Nikon, Tokyo, Japan). A $\beta$ and Iba-1 immunostaining were evaluated in the hemisphere sections, particularly in the cortex and the hippocampus. All sections were randomly numbered and analyzed independently by two observers, who were blinded to the treatment and time points. The numbers of $A \beta$ plaques and Iba-1-positive cells in the cortex andhippocampus were counted under a microscope at 50xmagnification. Small $A \beta$ plaques with a dense core and larger plaques with a dense core and a large halo of diffuse amyloid were counted. Small areas or spots of $A \beta$ staining, smaller than a cellular nucleus (approximately $10 \mu \mathrm{m}$ of diameter), and slightly stained diffuse amyloid without a dense core were classified as unclear deposition and were not counted. Furthermore, images of the hemisphere sections were captured using a Nikon Coolscope (Nikon) with fixed parameters. The cortex and the hippocampus were outlined on the images and analyzed using MetaMorph Offline 7.1 software (Molecular Devices, Toronto, Canada). The percentage areas of A 3 , Iba-1, CD206, and CD206+lba-1 in the regions of interest were determined using color threshold segmentation. All parameters were fixed for all images of a specific stain. Results are presented as the arithmetic mean of plaque/cell counts or percentage areas of immunoreactivity (IR) in an area of interest in the cross-sections and the standard error of the mean (SEM). Additionally, the ratios of CD206 immunoreactivity to Iba-1 IR and the ratios of double staining IR to Iba- 1 or $A \beta$ IR were calculated and presented in bar graphs.

\section{Immunofluorescence and confocal analysis}

For the NF-KB activation assay, vehicle-, A $\beta$-, and zerumbone-treated N9 cells were plated in confocal cell culture dishes. The cells were then fixed with ice-cold methanol, permeabilized with $0.25 \%$ Triton $X-$ $100 /$ TBST, and blocked with 1\% BSA in TBST for 1 hour. The cells were incubated with an antip65/RelA antibody (1:100, Abcam) for $2 \mathrm{~h}$ at room temperature and Alexa Fluor 647-conjugated secondary antibodies (1:1000, Cell Signaling Technology, Beverly, MA, USA) at room temperature for 1 hour. Finally, the nuclei were stained with 4', 6-diamidino-2-phenyl-indole (DAPI; SouthernBiotech, Birmingham, Ala, USA). Confocal microscopy was carried out using a Zeiss Axiovert system (LSM510; Carl Zeiss, Jena, Germany). 
To detect $A \beta$ in brain tissue, anesthetized animals were perfused transcardially with $4 \%$ paraformaldehyde. The brains were immediately removed, post-fixed in the same paraformaldehyde solution, and transferred to $30 \%$ sucrose solution at $4{ }^{\circ} \mathrm{C}$. The specimens were then embedded in TissueTek® O. C.T compound and frozen at $-80^{\circ} \mathrm{C}$. Specimens were cut into $25-\mu \mathrm{m}$-thick sections by a freezing microtome (CM1860; Leica, Wetzlar, Germany) and incubated overnight at $4{ }^{\circ} \mathrm{C}$ with antibodies against $A \beta$ (1:200, Abcam, lba-1, or glial fibrillary acidic protein (GFAP; 1:500, Novus Biologicals, Abingdon, UK). After washing, the sections were incubated with Alexa Fluor-conjugated secondary antibodies for 1 hour at room temperature. Cell nuclei were stained with DAPI. Images of each section were captured using a fluorescence microscope (Leica) by investigators blinded to the experimental groups.

To analyze microglial morphology, images were captured using a confocal microscope (LSM800, Zeiss) with 20x magnification. ImageJ (Loci, Madison, WI, USA) was used to analyze the shape of twodimensional somatic projections in confocal images of Iba-1-immunostained microglia based on maximum length $(\mathrm{L})$ and projection area $(\mathrm{A})^{[55]}$.

\section{Statistical analysis}

Differences in plaque/cell counts, areas of staining, and nest construction scores between the vehicleand zerumbone-treated groups were analyzed by the Mann-Whitney $U$ test, a nonparametric $t$ test, using Graph Pad Prism 5.0 software (San Diego, CA, USA). The data are represented as mean \pm SEM. For all statistical analyses, a $p$ value $<0.05$ was considered statistically significant.

\section{Results}

\section{Zerumbone reduces inflammation and promotes the phenotypic conversion of microglia in vitro}

The in vitro anti-inflammatory effects of zerumbone were analyzed using the murine N9 microglial cell line and primary microglia. LPS was used to induce inflammatory microglial activation ${ }^{[56,57]}$. LPSstimulated N9 microglial cells exhibited increased NO production (Figure 2A) and mRNA expression of $I L-1 \beta, I L-6$, iNOS, and TNF- $\alpha$ (Figure 2B), which are characteristic markers of the pro-inflammatory phenotype and thus indicate inflammatory microglial activation. Following LPS stimulation, zerumbone treatment significantly reduced NO production and dose-dependently decreased the mRNA levels of IL$1 \beta, I L-6$, iNOS, and TNF-a, suggesting that zerumbone has an anti-inflammatory effect on microglia. The mRNA levels of CD206, IL-10, and ARG-1, markers of the anti-inflammatory phenotype were significantly increased by zerumbone administration, indicating that zerumbone promotes a switch in microglial phenotype from the classic pro-inflammatory phenotype to the anti-inflammatory phenotype.

Furthermore, primary microglia were isolated from mouse brains to identify the effects of zerumbone in vitro. First, the purity of primary microglia was identified using flow cytometry, and CD $11 \mathrm{~b}^{+} / \mathrm{CD} 45^{\text {low }}$ microglia accounted for over $85 \%$ of the cells assayed (Figure 2C). As shown in Figures 2D and E, 
compared to the control cells, neither the numbers nor the viabilities of $A \beta$ - or zerumbone-treated microglia showed significant differences. The Aß-treated primary microglia exhibited increased NO production and mRNA expression of inflammatory factors including IL-1 $1 \beta$, IL-6, iNOS, and TNF-a. Zerumbone also dose-dependently increased the mRNA levels of anti-inflammatory factors such as CD206, IL-10, and ARG-1 (Figures 2F and G). The expression levels of IL-1 $1 \beta$, TNF-a, and IL-10 in primary microglia were detected using ELISA(Figure $2 \mathrm{H})$. Zerumbone significantly reduced the production of IL-1 $\beta$ and TNF-a. Additionally, zerumbone-treated microglia exhibited significantly increased IL-10 production compared to $A \beta$ treated microglia. Therefore, zerumbone exhibited anti-inflammatory activity and induced a switch in microglial polarization towards the anti-inflammatory phenotype, suggesting that it may have further applications in neuroinflammation-related diseases. The effects of zerumbone on microglial $A \beta$ phagocytosis were investigated using flow cytometry. Zerumbone-treated microglia exhibited increased $A \beta$ phagocytosis (Figure 2I).

\section{Zerumbone attenuates $A \beta$-induced MAPK/NF-KB activation in microglia}

Recent studies have indicated that zerumbone is a potent suppressor of the p38 MAPK/NF-KB signaling pathway ${ }^{[35,58]}$. Hence, we investigated the effects of zerumbone on the expression of PGE2, Cox -2 , and mPGES-1, which are all related to P38 MAPK, and four important mediators of the MAPK/NF-KB pathway in $A \beta$ treated microglia. Treatment with zerumbone suppressed the expression of PGE2, Cox-2, mPGES1, and the phosphorylated forms of ERK1/2, p38 MAPK, inhibitor of kappa B alpha (IKBa), and p65 NF-KB compared to treatment with $A \beta$ (Figures $3 A-D)$. As shown in Figure $3 E, A B$ induced the translocation of $p 65$ NF-KB into the nucleus, and zerumbone treatment significantly reduced this translocation.

To provide further evidence that the anti-inflammatory activity of zerumbone is related to inhibition of the ERK/p38 MAPK/NF-KB signaling pathway, we further inspected the effect of ERK/p38 MAPK/NF-KBspecific inhibitors on the concentrations of cytokines in the cell culture supernatants of microglia. As shown in Figure 3F, U0126 (an ERK inhibitor), SB202190 (a p38 inhibitor), and BAY 11-7082 (an NF-KB inhibitor) blocked the $A \beta$-stimulated up-regulation of IL- $\beta$ and TNF-a production. Similarly, the $A \beta-$ induced decrease in IL-10 production was also reversed by U0126, SB202190, and BAY 11-7082. Interestingly, when microglia were treated with zerumbone, none of the three inhibitors altered the secretion of inflammatory factors. These results suggested that zerumbone induced a switch in microglial polarization towards the anti-inflammatory phenotype by downregulating the $A \beta$ stimulated activation of the ERK/p38 MAPK/NF-KB signaling pathway in microglia.

\section{Zerumbone treatment attenuates the activation of MAPKs in microglia from APP/PS1 transgenic AD model mice}


We further investigated the activation of the ERK/P38MAPK/NF-KB signaling pathway in microglia of vehicle- and zerumbone-treated APP/PS1 transgenic AD model mice. The microglia isolated from zerumbone-treated mice exhibited decreased p-ERK $1 / 2$ expression compared to those isolated from vehicle-treated mice (Figures $3 \mathrm{G}$ and $\mathrm{H}$ ). Western blot analysis revealed that the expression of p-p38 was significantly decreased in microglia of zerumbone-treated APP/PS1 mice. Moreover, zerumbone significantly suppressed the phosphorylation of p65 NF-KB in microglia of APP/PS1 mice. These results indicate that zerumbone attenuates the activation of the MAPK/NF-KB signaling pathway in microglia of APP/PS1 transgenic AD model mice.

\section{Zerumbone treatment alleviates behavioral impairments in APP/PS1 transgenic AD model mice}

To assess the influence of zerumbone treatment on nesting behavior, a nest construction assay was conducted involving a 3-point scoring system. In one of our previous studies, we showed that the nesting ability of transgenic APP/PS1 mice was impaired ${ }^{[59]}$. At day 0 (before zerumbone treatment), no significant difference was observed between the vehicle- and zerumbone-treated mice with respect to nest construction score. Similarly, after ten days of treatment (day 10), no significant difference in nest construction score was noted between these two groups. At day 20 , however, a significant difference was observed in the nest construction scores of vehicle- and zerumbone-treated mice (Figure 4A). The ADcontrol mice investigated and slightly bit the paper towels, but did not destroy them. The towels were found distributed throughout the cage, and were not grouped into a corner. In contrast, the zerumbonetreated mice bit the paper towels, tore them into small pieces, and grouped them into a corner of the cage.

In the social interaction assay, the movements of the mice were recorded by two cameras: a verticallyplaced camera which was used to calculate the distances traveled by the mice, and a camera placed at the side of the cage which was used to count the numbers of individual and interactive behaviors. Both cameras were adjusted to a suitable height to ensure that all animal movements were captured. The distances traveled by the animals, according to $X / Y$ coordinates, were transformed into actual distances (pixel to $\mathrm{cm}$ ). The distances traveled by the vehicle- and zerumbone-treated mice were not significantly different before or after treatment (Figure 4B), indicating that the motor function of mice in both groups was normal and was not affected by the treatment. Two unfamiliar mice placed in the same cage will often display high levels of interaction. The videos were analyzed to determine the frequency of carefully defined behavioral events. Prior to treatment, the frequency of interactive behaviors did not significantly differ between the vehicle- and zerumbone-treated mice. Following 20 days of treatment, resident zerumbone-treated APP/PS1 mice showed a significantly higher frequency of interactive behaviors compared to vehicle-treated mice (Figure 4C).

In the novel object recognition test, WT mice explored the novel object for a longer time period and exhibited a RI of approximately $81 \%$, indicating their ability to remember the familiar object. In contrast, APP/PS1 mice exhibited a significantly lower RI of $48 \%$, demonstrating that the cognitive function of 
these animals was impaired. When given daily for 20 days, zerumbone significantly increased the RI of APP/PS1 mice to approximately $78 \%$, showing that zerumbone ameliorated cognitive impairments in these mice(Figure 4D).

The MWM test is one of the most sensitive tests for AD-like deficits as it examines the function of the hippocampus, the region of the brain most affected in AD. To assess hippocampal spatial memory deficits, the mice were placed into a water tank, and the length of time it took them to locate the hidden platform was recorded ${ }^{[60,61]}$. The performance of mice with or without zerumbone treatment was evaluated. There were no significant differences between vehicle- and zerumbone-treated APP/PS1 mice, indicating that these animals had similar motor and visual capabilities. The escape latencies of each mouse were compared to assess the learning and memory ability of the mice. The vehicle-treated APP/PS1 mice exhibited a significantly increased escape latency compared to WT mice, demonstrating that the learning ability of these animals was impaired. Zerumbone-treated APP/PS1 mice performed significantly better and exhibited a significantly reduced escape latency compared to the controls (Figure $4 \mathrm{E})$.

\section{Zerumbone treatment reduces microglial activation and the number of amyloid plaques in APP/PS1 transgenic AD model mice}

In APP/PS1 AD model mice, amyloid plaques were spread throughout the entire cortex. Some plaques were large and had a dense core and large area of diffused amyloid, but small plaques with a dense core were also observed (Figure 5A). Plaque density was generally lower in the hippocampus than in the cortex (Figure $5 \mathrm{E}$ ). Compared with vehicle-treated mice, there were more $A \beta$ plaques with fewer branches and smaller size in zerumbone-treated mice (Figures $5 B, F$, and M). Zerumbone treatment attenuated neuropathological histological changes compared to vehicle-treated APP/PS1 mice. Zerumbone treatment significantly reduced the numbers of plaques in the cortex and the hippocampus (Figure 5I), and substantially decreased the areas of $A \beta I R$ in the cortex and the hippocampus (Figure $5 \mathrm{~J}$ ).

In comparison to $A \beta$ staining, amoeboid Iba-1-positive microglia were mostly found clustered around amyloid plaques in both the cortex and hippocampus (Figures $5 \mathrm{C}$ and $\mathrm{G}$ ). Following zerumbone treatment, the number of Iba-1-positive cells was reduced, especially in the cortex, and these cells were less clustered around amyloid plaques (Figures 5D and $\mathrm{H}$ ). Further analysis showed that the percentage areas of Iba-1 IR in the cortex and hippocampus were significantly reduced (Figure 5K). These results indicate that zerumbone reduced the general activation of Iba-1-positive microglia. In addition to microglia, we also assessed astrocytic GFAP staining by immunofluorescence analysis. As shown in Figure $5 \mathrm{~L}$, there were no significant differences between vehicle- and zerumbone treated APP/PS1 mice with respect to astrocytic GFAPstaining. 
We also assessed the distinct activation of $\mathrm{Iba}-1^{+}$microglia by evaluating microglial shape using image analysis of two-dimensional somatic projections. Shape parameters were calculated based on the maximum length $(\mathrm{L})$ and projection area $(\mathrm{A})$ of individual microglia. Activated microglia exhibit a decreased somatic shape index (L/A). As shown in Figure 5M, the L/A ratio of microglia from zerumbonetreated mice was smaller than that of microglia from vehicle-treated mice. These results suggest that zerumbone treatment activated microglia in APP/PS1 mice. The co-labeling of A 3 and lba-1 also showed that zerumbone treatment increased the phagocytosis of $A \beta$ by $\mathrm{Iba}-1^{+}$microglia, decreasing the size of $A \beta$ plaques (Figure $5 \mathrm{~N}$ ). Taken together, these results demonstrate that although the total number of generally activated microglia was reduced by zerumbone, $A \beta$ phagocytosis and the distinct activation of microglia were promoted by zerumbone treatment.

\section{Zerumbone treatment increases the proportion of anti- inflammatory microglia in APP/PS1 transgenic AD model mice}

It has been shown that CD206 is mainly expressed by alternatively activated anti-inflammatory (M2) macrophages/microglia, and can therefore be used as a marker of these particular cell types ${ }^{[54]}$. Although CD206 is a marker of anti-inflammatory microglia, it may also be expressed by non-monocytes. Therefore, in addition to CD206 immunostaining (Figure 6A), Iba-1+CD206 (Figure 6B), lba-1+A (Figure $6 C$ ), and CD206+A $($ Figure 6D) double immunostaining were also conducted (IHC). Zerumbone treatment only slightly increased the numbers of $\mathrm{CD}^{206^{+}}$microglia-like cells in cortex or hippocampus (data not shown). The areas of CD206 IR and Iba-1+CD206 double IR in the cortex were also only slightly increased following zerumbone treatment (Figure 6E). Given that the area of $A \beta I R$ and the total number of microglia were reduced following zerumbone treatment, ratios of CD206 and Iba-1+CD206 IR areas compared to Iba- 1 IR and A $\beta$ IR were further analyzed. The ratios of the area of CD206 IR to the areas of Iba- 1 IR or $A \beta$ IR, the ratios of the area of Iba $-1+C D 206$ double staining IR to the areas of Iba- 1 IR or $A \beta$ IR were all significantly increased (Figures $6 \mathrm{~F}$ and $\mathrm{G}$ ). Our results were further confirmed by immunofluorescence staining and analysis, as shown in Figure $6 \mathrm{H}$. All these results indicate that zerumbone treatment increased the proportion of anti-inflammatory microglia.

\section{Discussion}

In this study, we demonstrated that zerumbone suppressed neuroinflammation and induced a switch in microglial phenotype from the classic inflammatory phenotype to the alternative anti-inflammatory phenotype by inhibiting the MAPK/NF-KB signaling pathway in vitro. In a mouse model of AD, zerumbone significantly ameliorated deficits in both non-cognitive and cognitive behaviors. It also significantly reduced $\beta$-amyloid deposition, attenuated pro-inflammatory microglial activation, and increased the proportion of anti-inflammatory microglia among all activated microglia in the cortex and hippocampus of APP/PS1 mice. Meanwhile, the expression of key molecules of the MAPK signaling pathway, for 
example p38 and extracellular signal-regulated kinase, was also down-regulated in microglia isolated from the brains of zerumbone-treated APP/PS1 mice.

Increasing evidence has shown that the MAPK signaling pathway plays a crucial role in the pathophysiology of $A D$; activation of this pathway has been observed in the postmortem brains of $A D$ patients and animal models of $A D^{[25,26,62]}$. MAPK inactivation in the prefrontal cortex was shown to relieve memory deficits in $A D$ model mice ${ }^{[27,28]}$. The activation of ERK and p38 MAPK is increased in A exposed microglia and mouse models of $A D$ with more advanced amyloid pathology ${ }^{[24]}$. Decreased ERK and $\mathrm{p} 38$ MAPK activity reduced $A \beta$ neurotoxicity and reversed memory impairments in mouse models of $A D^{[27,28,63,64]}$. Moreover, $\mathrm{p} 38 \mathrm{MAPK}$ has been found to play an essential role in the regulation of proinflammatory signaling networks and in the biosynthesis of cytokines, including TNF-a and IL -1 , in immune cells ${ }^{[65]}$. p38 MAPK is also highly expressed in brain regions that are crucial for learning and memory in patients with $A D$ and epileptic seizures, and is likely involved in higher brain functions ${ }^{[66]}$. In addition, a core downstream signaling molecule of the MAPK pathway, NF-KB, a major inflammatory signaling molecule and transcription factor, is activated in the brains of $A D$ patients ${ }^{[67,68]}$, and is thought to play a key role in $A D$ development and cognitive impairments ${ }^{[69,70]}$. Inhibition of ERK and p38 MAPK has been reported to suppress A $\beta$-induced NF-KB transactivation ${ }^{[71,72]}$, and NF-KB has also been identified as a target for early intervention in $A D^{[70]}$. Therefore, inhibition of ERK/p38 MAPK may be a promising therapeutic strategy for the treatment of $A D^{[27,28]}$. Many studies have been conducted into the development and design of novel p38aMAPK inhibitors and several have presented significant therapeutic effects in animal models of $A D{ }^{[73,74]}$. Inhibiting both ERK and p38 MAPK will undoubtedly have a more significant therapeutic effect on AD. Recent studies have focused on the suppression of activated glial cell-mediated neuroinflammation via indirect MAPK inhibitors such as natural terpenoids ${ }^{[75,76]}$. The subtropical ginger sesquiterpene zerumbone has exhibited notable antiinflammatory effects by suppressing the MAPK signaling pathway and NF-kB activation in different cell types ${ }^{[77][78]}$. In accordance with previous studies, zerumbone inhibited the ERK/p38 MAPK signaling pathway and thereby exhibited anti-neuroinflammatory activity in cultured microglial cells in this study. This prompted us to further investigate its potential therapeutic effects in an animal model of AD.

Notably, zerumbone ameliorated behavioral deficits in APP/PS1 mice and significantly decreased A $\beta$ deposition and neuroinflammation in the brains of these mice. Patients with AD typically exhibit cognitive and non-cognitive impairments. Toxic A $\beta$ peptides, APP peptides, and inflammatory responses have been shown to be directly associated with impairments in cognitive function and non-cognitive behaviors ${ }^{[79]}$. Cognitive impairments in animal models, such as memory and learning deficits, are typically evaluated using the novel object recognition task and the MWM test ${ }^{[80]}$. Affiliative nesting and interactive social behaviors are considered rodent analogues of the non-cognitive behaviors that are characteristically compromised in human $A D^{[81]}$. Impairments in these two non-cognitive behaviors have been reported in transgenic APP/PS1 mice ${ }^{[59]}$. The hippocampus, prefrontal cortex, and other brain regions are thought to be responsible for cognitive function and nesting ability $[49,82]$, while the frontal cortex is believed to be 
responsible for social memory and social interaction ${ }^{[83,84]}$. Therefore, the cognitive function, nesting ability, and social behavior of APP/PS1 mice may also be impaired by pathological changes in these brain regions, namely toxic $A \beta$ deposition and neuroinflammation. Given that zerumbone treatment attenuated $A \beta$ deposition and reduced neuroinflammation in the cortex and hippocampus after a relatively short period, these neuropathological improvements may have contributed to the improved memory and learning ability, nesting ability, and social interactive behavior of the APP/PS1 mice (Figure 4). These results demonstrated the therapeutic effect of zerumbone in this animal model of $A D$, and suggest that it may have beneficial effects in AD patients.

In addition to the suppression of neuroinflammation, our in vitro results suggested that the therapeutic effects of zerumbone may also be mediated via the switching of microglial phenotype. Previous studies have not directly specified the association of microglial phenotype with MAPK inactivation in AD pathology. The present study demonstrated that ERK/p38 MAPK signaling was affected by zerumbone treatment, with significantly decreased levels of p-p38 and p-ERK found in microglia isolated from zerumbone-treated APP/PS1 mice (Figure 3G). Importantly, changes in microglial phenotype were closely associated with the neuroprotective effect of zerumbone. Microglial activation and the expression of inflammatory molecules are directly involved in neurodegenerative pathology and in the development of neuroinflammation ${ }^{[85]}$. A previous study reported a direct correlation between inflammatory status and amyloid load in the cell culture supernatant of organotypic brain slice cultures from a similar transgenic $A D$ mouse model using multi-plex cytokine array analysis ${ }^{[86]}$. After we observed an ameliorated inflammatory milieu by zerumbone in our microglial culture, histological assays of brain tissue from APP/PS1 mice showed that zerumbone significantly attenuated microglial inflammatory activation in both the cortex and hippocampus (Figure 4). This indicates that zerumbone controls neuroinflammation and may also ameliorate other pathological changes, since attenuated neuroinflammation is known to contribute to reduced amyloid plaque accumulation ${ }^{[87]}$. Interestingly, we further observed that zerumbone switched microglial phenotype from the inflammatory phenotype to the anti-inflammatory phenotype in vitro (Figure 2B, G and $\mathrm{H}$ ). Furthermore, although the total number of activated microglia reduced, the proportion of anti-inflammatory microglia increased in the brains of zerumbone-treated APP/PS1 mice (Figure 6). Additionally, microglial $A \beta$ phagocytosis was increased since $A \beta$ deposition around activated microglia was significantly reduced (Figure 5). These results suggest that zerumbone may play a therapeutic role beyond its anti-neuroinflammatory potential, since alternatively activated (M2) microglia have been reported to possess a significantly increased capacity for $A \beta$ phagocytosis compared to classically activated (M1) microglia ${ }^{[17,88]}$, and were associated with decreased $A \beta$ deposition in a previous study of APP/PS1 mice ${ }^{[89]}$. Furthermore, our in vitro results suggest that the zerumbone-induced switching of microglial phenotype towards the anti-inflammatory phenotype was mediated by downregulation of the ERK/p38 MAPK signaling pathway in microglia.

p38 MAPK is reported to be significantly involved in microglial activation and neuroinflammation ${ }^{[90]}$. p38a KO mice exhibit an increased tendency towards alternatively activated (M2) microglial polarization ${ }^{[29]}$, and suppressing p38 MAPK activation in glial cells alleviated neurotoxicity in a mouse 
model of $A D^{[75,91]}$. Recently, it has been found that inhibition of other MAPK signaling molecules, namely JNK and ERK, also promotes alternative (M2) microglial polarization and thereby inhibits neuroinflammation ${ }^{[30]}$. These results suggest that promoting anti-inflammatory (M2) microglial polarization by inhibiting MAPK signaling could be a promising treatment strategy for AD. Similarly, inhibition of the NF-KB pathway by certain non-steroidal anti-inflammatory drugs reduces the levels of pro-inflammatory cytokines and increases the levels of anti-inflammatory cytokines in microglia. This results in the recruitment of distinctly activated $A \beta$ phagocytic microglia and the amelioration of cognitive deficits in $A D$ animal models ${ }^{[92]}$, consistent with the previously established role of distinct microglial activation in $A D^{[85]}$.

Although we demonstrated that zerumbone ameliorated behavioral impairments and neuropathological changes in transgenic APP/PS1 mice by suppressing MAPK signaling, the specific binding site of zerumbone remains unknown. In recent years, increasing evidence has demonstrated that zerumbone has neuroprotective effects in different cells and experimental animals, but the molecular targets and potential mechanisms of action of zerumbone remain to be fully elucidated. There is no doubt that this will be the focus of our future studies.

\section{Conclusion}

In conclusion, we demonstrated that zerumbone exhibited neuroprotective effects in the transgenic APP/PS1 AD mouse model, ameliorating neuroinflammation and cerebral amyloidosis, thus restoring non-cognitive and cognitive behavioral impairments. This neuroprotective effect of zerumbone may result from its anti-neuroinflammatory activity. Notably, zerumbone switched classically activated proinflammatory microglia into anti-inflammatory microglia through regulating the ERK/p38 MAPK signaling pathway, thus enhancing the phagocytosis of $A \beta$. Taken together, these results suggest that zerumbone may be a promising therapeutic agent for the treatment of human AD (Figure 7).

\section{Abbreviations}

ARG-1, arginine-1; $A \beta, \beta$-amyloid; AD, Alzheimer's disease; APP, amyloid precursor protein; $B S A$, bovine serum albumin; $\mathrm{CCK}-8$, Cell Counting Kit-8; CMC, carboxymethylcellulose; CNS, central nervous system; Cox-2, cyclooxygenase-2; ELISA, enzyme-linked immunosorbent assay; ERK, extracellular signalregulated kinase; GFAP, glial fibrillary acidic protein; HBSS, Hank's Balanced Salt Solution; Iba-1, ionized calcium-binding adaptor molecule-1; IL, interleukin; iNOS, inducible nitric oxide synthase; JNK, c-Jun Nterminal kinase; LPS, lipopolysaccharide; MAPK, mitogen-activated protein kinase; microsomal prostaglandin E synthase-1 (mPGES-1); MWM, Morris water maze; NF-KB, nuclear factor-kappa B; NO, nitric oxide; PGE2, prostaglandin E2; PS1-21, presenilin 1-21; RI, recognition index; SEM, standard error of the mean; TNF- $a$, tumor necrosis factor- $a$

\section{Declarations}




\section{Ethics approval and consent to participate}

All experiments and protocols were licensed and approved by the local government in Germany, according to The German Animal Welfare Act (TierSchG) of 2006; or by Nanjing Medical University Animal Care and Use Committee in accordance with the regulations of the ethics committee of the International Association for the Study of Pain and the Guide for the Care and Use of Laboratory Animals (The Ministry of Science and Technology of China, 2006) in China.

\section{Consent for publication}

Not applicable.

\section{Availability of data and material}

The datasets generated and/or analyzed during the current study are available from the corresponding author on reasonable request.

\section{Competing interests}

The authors declare that they have no competing interests.

\section{Funding}

This work was supported by the National Natural Science Foundation of China (Grant No. 81571240 and 81771171) and the Jiangsu Provincial Innovation Team Program Foundation.

\section{Authors' contributions}

$Z-Y Z$ designed the experiments, obtained resources, and acquired funding. $Z-Y Z$ conducted the experiments with assistance from LL, X-HW, and X-JZ. LX, LL, X-HW, X-JZ, and Z-YZ collected the data and contributed to the statistical analysis. LX, C-LP, and Z-YZ analyzed the data and wrote the manuscript. All authors read and approved the final manuscript.

\section{Acknowledgements}

Not applicable.

\section{References}


1.Serrano-Pozo A, Frosch MP, Masliah E, Hyman BT: Neuropathological alterations in Alzheimer disease. Cold Spring Harb Perspect Med 2011, 1:a006189.

2.Klein WL, Stine WB, Jr., Teplow DB: Small assemblies of unmodified amyloid beta-protein are the proximate neurotoxin in Alzheimer's disease. Neurobiol Aging 2004, 25:569-580.

3.Park SK, Ha JS, Kim JM, Kang JY, Lee du S, Guo TJ, Lee U, Kim DO, Heo HJ: Antiamnesic Effect of Broccoli (Brassica oleracea var. italica) Leaves on Amyloid Beta (Abeta)1-42-Induced Learning and Memory Impairment. J Agric Food Chem 2016, 64:3353-3361.

4.Herrmann N, Chau SA, Kircanski I, Lanctot KL: Current and emerging drug treatment options for Alzheimer's disease: a systematic review. Drugs 2011, 71:2031-2065.

5.Hensley K: Neuroinflammation in Alzheimer's disease: mechanisms, pathologic consequences, and potential for therapeutic manipulation. J Alzheimers Dis 2010, 21:1-14.

6. Heneka MT, Carson MJ, El Khoury J, Landreth GE, Brosseron F, Feinstein DL, Jacobs AH, Wyss-Coray T, Vitorica J, Ransohoff RM, et al: Neuroinflammation in Alzheimer's disease. Lancet Neurol 2015, 14.388405.

7.Mawuenyega KG, Sigurdson W, Ovod V, Munsell L, Kasten T, Morris JC, Yarasheski KE, Bateman RJ: Decreased clearance of CNS beta-amyloid in Alzheimer's disease. Science 2010, 330:1774.

8.Minter MR, Taylor JM, Crack PJ: The contribution of neuroinflammation to amyloid toxicity in Alzheimer's disease. J Neurochem 2016, 136:457-474.

9.Martin-Moreno AM, Brera B, Spuch C, Carro E, Garcia-Garcia L, Delgado M, Pozo MA, Innamorato NG, Cuadrado A, de Ceballos ML: Prolonged oral cannabinoid administration prevents neuroinflammation, lowers beta-amyloid levels and improves cognitive performance in Tg APP 2576 mice. J Neuroinflammation 2012, 9:8.

10.Pan RY, Ma J, Kong XX, Wang XF, Li SS, Qi XL, Yan YH, Cheng J, Liu Q, Jin W, et al: Sodium rutin ameliorates Alzheimer's disease-like pathology by enhancing microglial amyloid-beta clearance. Sci Adv 2019, 5:eaau6328.

11. Hjorth E, Frenkel D, Weiner H, Schultzberg M: Effects of immunomodulatory substances on phagocytosis of abeta(1-42) by human microglia. Int J Alzheimers Dis 2010, 2010.

12.Adolfsson O, Pihlgren M, Toni N, Varisco Y, Buccarello AL, Antoniello K, Lohmann S, Piorkowska K, Gafner V, Atwal JK, et al: An effector-reduced anti-beta-amyloid (Abeta) antibody with unique abeta binding properties promotes neuroprotection and glial engulfment of Abeta. J Neurosci 2012, 32:96779689. 
13.Elmore MR, Najafi AR, Koike MA, Dagher NN, Spangenberg EE, Rice RA, Kitazawa M, Matusow B, Nguyen $\mathrm{H}$, West BL, Green KN: Colony-stimulating factor 1 receptor signaling is necessary for microglia viability, unmasking a microglia progenitor cell in the adult brain. Neuron 2014, 82:380-397.

14.Wes PD, Sayed FA, Bard F, Gan L: Targeting microglia for the treatment of Alzheimer's Disease. Glia $2016,64: 1710-1732$.

15.laccarino HF, Singer AC, Martorell AJ, Rudenko A, Gao F, Gillingham TZ, Mathys H, Seo J, Kritskiy O, Abdurrob F, et al: Gamma frequency entrainment attenuates amyloid load and modifies microglia. Nature 2016, 540:230-235.

16.Hu X, Leak RK, Shi Y, Suenaga J, Gao Y, Zheng P, Chen J: Microglial and macrophage polarization-new prospects for brain repair. Nat Rev Neurol 2015, 11:56-64.

17.Cherry JD, Olschowka JA, O’Banion MK: Neuroinflammation and M2 microglia: the good, the bad, and the inflamed. J Neuroinflammation 2014, 11:98.

18.David S, Kroner A: Repertoire of microglial and macrophage responses after spinal cord injury. Nat Rev Neurosci 2011, 12:388-399.

19.Bok E, Chung YC, Kim KS, Baik HH, Shin WH, Jin BK: Modulation of M1/M2 polarization by capsaicin contributes to the survival of dopaminergic neurons in the lipopolysaccharide-lesioned substantia nigra in vivo. Exp Mol Med2018, 50:76.

20.Saijo K, Glass CK: Microglial cell origin and phenotypes in health and disease. Nat Rev Immunol 2011, 11:775-787.

21.Mantovani A, Biswas SK, Galdiero MR, Sica A, Locati M: Macrophage plasticity and polarization in tissue repair and remodelling. J Pathol 2013, 229:176-185.

22.Pearson G, Robinson F, Beers Gibson T, Xu BE, Karandikar M, Berman K, Cobb MH: Mitogen-activated protein (MAP) kinase pathways: regulation and physiological functions. Endocr Rev 2001, 22:153-183.

23.Dimri M, Humphries A, Laknaur A, Elattar S, Lee TJ, Sharma A, Kolhe R, Ande S: Nqo1 ablation inhibits activation of the PI3K/Akt and MAPK/ERK pathways and blocks metabolic adaptation in hepatocellular carcinoma. Hepatology 2019.

24.Koistinaho M, Koistinaho J: Role of p38 and p44/42 mitogen-activated protein kinases in microglia. Glia 2002, 40:175-183.

25.Sun A, Liu M, Nguyen XV, Bing G: P38 MAP kinase is activated at early stages in Alzheimer's disease brain. Exp Neurol 2003, 183:394-405. 
26.Schnoder L, Hao W, Qin Y, Liu S, Tomic I, Liu X, Fassbender K, Liu Y: Deficiency of Neuronal p38alpha MAPK Attenuates Amyloid Pathology in Alzheimer Disease Mouse and Cell Models through Facilitating Lysosomal Degradation of BACE1. J Biol Chem 2016, 291:2067-2079.

27.Feld M, Krawczyk MC, Sol Fustinana M, Blake MG, Baratti CM, Romano A, Boccia MM: Decrease of ERK/MAPK overactivation in prefrontal cortex reverses early memory deficit in a mouse model of Alzheimer's disease. J Alzheimers Dis 2014, 40:69-82.

28.Munoz L, Ammit AJ: Targeting p38 MAPK pathway for the treatment of Alzheimer's disease. Neuropharmacology 2010, 58:561-568.

29.Bachstetter AD, Rowe RK, Kaneko M, Goulding D, Lifshitz J, Van Eldik LJ: The p38alpha MAPK regulates microglial responsiveness to diffuse traumatic brain injury. J Neurosci 2013, 33:6143-6153.

30.Zhang B, Wei YZ, Wang GQ, Li DD, Shi JS, Zhang F: Targeting MAPK Pathways by Naringenin Modulates Microglia M1/M2 Polarization in Lipopolysaccharide-Stimulated Cultures. Front Cell Neurosci 2018, 12:531.

31.Kitayama T, Okamoto T, Hill RK, Kawai Y, Takahashi S, Yonemori S, Yamamoto Y, Ohe K, Uemura S, Sawada S: Chemistry of Zerumbone. 1. Simplified Isolation, Conjugate Addition Reactions, and a Unique Ring Contracting Transannular Reaction of Its Dibromide. J Org Chem 1999, 64.2667-2672.

32. Haque MA, Jantan I, Arshad L, Bukhari SNA: Exploring the immunomodulatory and anticancer properties of zerumbone. Food Funct 2017, 8:3410-3431.

33.Ashraf SM, Sebastian J, Rathinasamy K: Zerumbone, a cyclic sesquiterpene, exerts antimitotic activity in HeLa cells through tubulin binding and exhibits synergistic activity with vinblastine and paclitaxel. Cell Prolif 2019, 52:e12558.

34.Yob NJ, Jofrry SM, Affandi MM, Teh LK, Salleh MZ, Zakaria ZA: Zingiber zerumbet (L.) Smith: A Review of Its Ethnomedicinal, Chemical, and Pharmacological Uses. Evid Based Complement Alternat Med 2011, 2011:543216.

35. Haque MA, Jantan I, Harikrishnan $\mathrm{H}$ : Zerumbone suppresses the activation of inflammatory mediators in LPS-stimulated U937 macrophages through MyD88-dependent NF-kappaB/MAPK/PI3K-Akt signaling pathways. Int Immunopharmacol 2018, 55.312-322.

36.Kim MJ, Yun JM: Molecular Mechanism of the Protective Effect of Zerumbone on LipopolysaccharideInduced Inflammation of THP-1 Cell-Derived Macrophages. J Med Food 2019, 22:62-73.

37.Chen BY, Lin DP, Wu CY, Teng MC, Sun CY, Tsai YT, Su KC, Wang SR, Chang HH: Dietary zerumbone prevents mouse cornea from UVB-induced photokeratitis through inhibition of NF-kappaB, iNOS, and TNFalpha expression and reduction of MDA accumulation. Mol Vis 2011, 17:854-863. 
38.Gopalsamy B, Farouk AAO, Tengku Mohamad TAS, Sulaiman MR, Perimal EK: Antiallodynic and antihyperalgesic activities of zerumbone via the suppression of $I L-1$ beta, $I L-6$, and TNF-alpha in a mouse model of neuropathic pain. J Pain Res 2017, 10.2605-2619.

39.Lim CS, Jin DQ, Mok H, Oh SJ, Lee JU, Hwang JK, Ha I, Han JS: Antioxidant and antiinflammatory activities of xanthorrhizol in hippocampal neurons and primary cultured microglia. J Neurosci Res 2005, 82:831-838.

40.Shi C, Zheng DD, Wu FM, Liu J, Xu J: The phosphatidyl inositol 3 kinase-glycogen synthase kinase 3 beta pathway mediates bilobalide-induced reduction in amyloid beta-peptide. Neurochem Res 2012, 37.298-306.

41.Radde R, Bolmont T, Kaeser SA, Coomaraswamy J, Lindau D, Stoltze L, Calhoun ME, Jaggi F, Wolburg $\mathrm{H}$, Gengler S, et al: Abeta42-driven cerebral amyloidosis in transgenic mice reveals early and robust pathology. EMBO Rep 2006, 7:940-946.

42.Gengler S, Hamilton A, Holscher C: Synaptic plasticity in the hippocampus of a APP/PS1 mouse model of Alzheimer's disease is impaired in old but not young mice. PLoS One 2010, 5:e9764.

43.Lepore F, D'Alessandro G, Antonangeli F, Santoro A, Esposito V, Limatola C, Trettel F: CXCL 16/CXCR6 Axis Drives Microglia/Macrophages Phenotype in Physiological Conditions and Plays a Crucial Role in Glioma. Front Immunol 2018, 9.2750.

44.Lee JK, Tansey MG: Microglia isolation from adult mouse brain. Methods Mol Biol 2013, 1041:17-23.

45.Pan B, Yang L, Wang J, Wang Y, Wang J, Zhou X, Yin X, Zhang Z, Zhao D: C-Abl tyrosine kinase mediates neurotoxic prion peptide-induced neuronal apoptosis via regulating mitochondrial homeostasis. Mol Neurobiol 2014, 49:1102-1116.

46.Pan Y, Sun L, Wang J, Fu W, Fu Y, Wang J, Tong Y, Pan B: STI571 protects neuronal cells from neurotoxic prion protein fragment-induced apoptosis. Neuropharmacology 2015, 93:191-198.

47.Pan B, Zhang H, Cui T, Wang X: TFEB activation protects against cardiac proteotoxicity via increasing autophagic flux. J Mol Cell Cardiol 2017, 113:51-62.

48.Zhang H, Pan B, Wu P, Parajuli N, Rekhter MD, Goldberg AL, Wang X: PDE1 inhibition facilitates proteasomal degradation of misfolded proteins and protects against cardiac proteinopathy. Sci Adv 2019, 5:eaaw5870.

49.Wesson DW, Wilson DA: Age and gene overexpression interact to abolish nesting behavior in Tg2576 amyloid precursor protein (APP) mice. Behav Brain Res 2011, 216:408-413.

50.Bolivar VJ, Walters SR, Phoenix JL: Assessing autism-like behavior in mice: variations in social interactions among inbred strains. Behav Brain Res 2007, 176.21-26. 
51.Hibbits N, Pannu R, Wu TJ, Armstrong RC: Cuprizone demyelination of the corpus callosum in mice correlates with altered social interaction and impaired bilateral sensorimotor coordination. ASN Neuro $2009,1$.

52.de Chaumont F, Dallongeville S, Chenouard N, Herve N, Pop S, Provoost T, Meas-Yedid V, Pankajakshan P, Lecomte T, Le Montagner Y, et al: Icy: an open bioimage informatics platform for extended reproducible research. Nat Methods 2012, 9:690-696.

53.Zhang Z, Zhang ZY, Fauser U, Schluesener HJ: FTY720 ameliorates experimental autoimmune neuritis by inhibition of lymphocyte and monocyte infiltration into peripheral nerves. Exp Neurol 2008, 210:681690.

54.Rae F, Woods K, Sasmono T, Campanale N, Taylor D, Ovchinnikov DA, Grimmond SM, Hume DA, Ricardo SD, Little MH: Characterisation and trophic functions of murine embryonic macrophages based upon the use of a Csf1r-EGFP transgene reporter. Dev Biol 2007, 308.232-246.

55.Li D, Lang W, Zhou C, Wu C, Zhang F, Liu Q, Yang S, Hao J: Upregulation of Microglial ZEB1 Ameliorates Brain Damage after Acute Ischemic Stroke. Cell Rep 2018, 22:3574-3586.

56.Bolouri H, Savman K, Wang W, Thomas A, Maurer N, Dullaghan E, Fjell CD, Ek CJ, Hagberg H, Hancock $\mathrm{RE}$, et al: Innate defense regulator peptide 1018 protects against perinatal brain injury. Ann Neurol2014, 75.395-410.

57.Ekdahl CT, Claasen JH, Bonde S, Kokaia Z, Lindvall O: Inflammation is detrimental for neurogenesis in adult brain. Proc Natl Acad Sci U S A 2003, 100:13632-13637.

58.Lee CY, Chen SP, Su CH, Ho YC, Yang ML, Lee SS, Huang-Liu R, Yang CP, Chen CJ, Kuan YH: Zerumbone from Zingiber zerumbet Ameliorates Lipopolysaccharide-Induced ICAM-1 and Cytokines Expression via p38 MAPK/JNK-IkappaB/NF-kappaB Pathway in Mouse Model of Acute Lung Injury. Chin J Physio/ 2018, 61:171-180.

59.Zhang ZY, Schluesener HJ: Oral administration of histone deacetylase inhibitor MS-275 ameliorates neuroinflammation and cerebral amyloidosis and improves behavior in a mouse model. $J$ Neuropathol Exp Neurol 2013, 72:178-185.

60.Yao XQ, Jiao SS, Saadipour K, Zeng F, Wang QH, Zhu C, Shen LL, Zeng GH, Liang CR, Wang J, et al: p75NTR ectodomain is a physiological neuroprotective molecule against amyloid-beta toxicity in the brain of Alzheimer's disease. Mol Psychiatry 2015, 20:1301-1310.

61.Jiao SS, Yao XQ, Liu YH, Wang QH, Zeng F, Lu JJ, Liu J, Zhu C, Shen LL, Liu CH, et al: Edaravone alleviates Alzheimer's disease-type pathologies and cognitive deficits. Proc Natl Acad Sci U S A 2015, 112:5225-5230. 
62.Hensley K, Floyd RA, Zheng NY, Nael R, Robinson KA, Nguyen X, Pye QN, Stewart CA, Geddes J, Markesbery WR, et al: p38 kinase is activated in the Alzheimer's disease brain. J Neurochem 1999, 72.2053-2058.

63.Sun J, Nan G: The extracellular signal-regulated kinase 1/2 pathway in neurological diseases: $A$ potential therapeutic target (Review). Int J Mol Med 2017, 39:1338-1346.

64.Pei JJ, Braak H, An WL, Winblad B, Cowburn RF, Iqbal K, Grundke-lqbal I: Up-regulation of mitogenactivated protein kinases ERK1/2 and MEK1/2 is associated with the progression of neurofibrillary degeneration in Alzheimer's disease. Brain Res Mol Brain Res 2002, 109:45-55.

65.Yokota T, Wang Y: p38 MAP kinases in the heart. Gene 2016, 575:369-376.

66.Yasuda S, Sugiura H, Tanaka H, Takigami S, Yamagata K: p38 MAP kinase inhibitors as potential therapeutic drugs for neural diseases. Cent Nerv Syst Agents Med Chem 2011, 11:45-59.

67.Song XY, Hu JF, Sun MN, Li ZP, Zhu ZX, Song LK, Yuan YH, Liu G, Chen NH: IMM-H004, a novel coumarin derivative compound, attenuates the production of inflammatory mediatory mediators in lipopolysaccharide-activated BV2 microglia. Brain Res Bull2014, 106:30-38.

68.Shi ZM, Han YW, Han XH, Zhang K, Chang YN, Hu ZM, Qi HX, Ting C, Zhen Z, Hong W: Upstream regulators and downstream effectors of NF-kappaB in Alzheimer's disease. J Neurol Sci 2016, 366:127134.

69.Ju Hwang C, Choi DY, Park MH, Hong JT: NF-kappaB as a Key Mediator of Brain Inflammation in Alzheimer's Disease. CNS Neurol Disord Drug Targets 2019, 18:3-10.

70.Jones SV, Kounatidis I: Nuclear Factor-Kappa B and Alzheimer Disease, Unifying Genetic and Environmental Risk Factors from Cell to Humans. Front Immunol 2017, 8:1805.

71.Jang JH, Surh YJ: Beta-amyloid-induced apoptosis is associated with cyclooxygenase-2 upregulation via the mitogen-activated protein kinase-NF-kappaB signaling pathway. Free Radic Biol Med 2005, 38:1604-1613.

72.Chami L, Buggia-Prevot V, Duplan E, Del Prete D, Chami M, Peyron JF, Checler F: Nuclear factor-kappaB regulates betaAPP and beta- and gamma-secretases differently at physiological and supraphysiological Abeta concentrations. J Biol Chem 2012, 287.24573-24584.

73.Munoz L, Ralay Ranaivo H, Roy SM, Hu W, Craft JM, McNamara LK, Chico LW, Van Eldik LJ, Watterson DM: A novel p38 alpha MAPK inhibitor suppresses brain proinflammatory cytokine up-regulation and attenuates synaptic dysfunction and behavioral deficits in an Alzheimer's disease mouse model. J Neuroinflammation 2007, 4.21. 
74.Roy SM, Grum-Tokars VL, Schavocky JP, Saeed F, Staniszewski A, Teich AF, Arancio O, Bachstetter AD, Webster SJ, Van Eldik LJ, et al: Targeting human central nervous system protein kinases: An isoform selective p38alphaMAPK inhibitor that attenuates disease progression in Alzheimer's disease mouse models. ACS Chem Neurosci 2015, 6:666-680.

75.Lee JK, Kim NJ: Recent Advances in the Inhibition of p38 MAPK as a Potential Strategy for the Treatment of Alzheimer's Disease. Molecules 2017, 22.

76.de las Heras B, Hortelano S: Molecular basis of the anti-inflammatory effects of terpenoids. Inflamm Allergy Drug Targets 2009, 8.28-39.

77.Murakami A, Takahashi D, Kinoshita T, Koshimizu K, Kim HW, Yoshihiro A, Nakamura Y, Jiwajinda S, Terao J, Ohigashi H: Zerumbone, a Southeast Asian ginger sesquiterpene, markedly suppresses free radical generation, proinflammatory protein production, and cancer cell proliferation accompanied by apoptosis: the alpha,beta-unsaturated carbonyl group is a prerequisite. Carcinogenesis 2002, 23:795802.

78.Takada Y, Murakami A, Aggarwal BB: Zerumbone abolishes NF-kappaB and IkappaBalpha kinase activation leading to suppression of antiapoptotic and metastatic gene expression, upregulation of apoptosis, and downregulation of invasion. Oncogene 2005, 24:6957-6969.

79.0wnby RL: Neuroinflammation and cognitive aging. Curr Psychiatry Rep 2010, 12:39-45.

80.Rodriguiz RM, Wetsel WC: Assessments of Cognitive Deficits in Mutant Mice. In Animal Models of Cognitive Impairment. Edited by Levin ED, Buccafusco JJ. Boca Raton (FL); 2006: Frontiers in Neuroscience]..

81.Alexander G, Hanna A, Serna V, Younkin L, Younkin S, Janus C: Increased aggression in males in transgenic Tg2576 mouse model of Alzheimer's disease. Behav Brain Res 2011, 216:77-83.

82.Deacon RM: Assessing nest building in mice. Nat Protoc 2006, 1:1117-1119.

83.Bechara A: The neurology of social cognition. Brain 2002, 125:1673-1675.

84.Hari R, Kujala MV: Brain basis of human social interaction: from concepts to brain imaging. Physiol Rev 2009, 89:453-479.

85.Hemonnot AL, Hua J, Ulmann L, Hirbec H: Microglia in Alzheimer Disease: Well-Known Targets and New Opportunities. Front Aging Neurosci 2019, 11.233.

86.Patel NS, Paris D, Mathura V, Quadros AN, Crawford FC, Mullan MJ: Inflammatory cytokine levels correlate with amyloid load in transgenic mouse models of Alzheimer's disease. J Neuroinflammation 2005, 2:9. 
87.Tweedie D, Ferguson RA, Fishman K, Frankola KA, Van Praag H, Holloway HW, Luo W, Li Y, Caracciolo

L, Russo I, et al: Tumor necrosis factor-alpha synthesis inhibitor 3,6'-dithiothalidomide attenuates markers of inflammation, Alzheimer pathology and behavioral deficits in animal models of neuroinflammation and Alzheimer's disease. J Neuroinflammation 2012, 9:106.

88.Mandrekar-Colucci S, Karlo JC, Landreth GE: Mechanisms underlying the rapid peroxisome proliferator-activated receptor-gamma-mediated amyloid clearance and reversal of cognitive deficits in a murine model of Alzheimer's disease. J Neurosci 2012, 32:10117-10128.

89. Heneka MT, Kummer MP, Stutz A, Delekate A, Schwartz S, Vieira-Saecker A, Griep A, Axt D, Remus A, Tzeng TC, et al: NLRP3 is activated in Alzheimer's disease and contributes to pathology in APP/PS1 mice. Nature 2013, 493:674-678.

90.Bhat NR, Feinstein DL, Shen Q, Bhat AN: p38 MAPK-mediated transcriptional activation of inducible nitric-oxide synthase in glial cells. Roles of nuclear factors, nuclear factor kappa $B$, cAMP response element-binding protein, CCAAT/enhancer-binding protein-beta, and activating transcription factor-2. J Biol Chem 2002, 277:29584-29592.

91.Guo L, Du H, Yan S, Wu X, McKhann GM, Chen JX, Yan SS: Cyclophilin D deficiency rescues axonal mitochondrial transport in Alzheimer's neurons. PLoS One 2013, 8:e54914.

92. Valerio A, Boroni F, Benarese M, Sarnico I, Ghisi V, Bresciani LG, Ferrario M, Borsani G, Spano P, Pizzi M: NF-kappaB pathway: a target for preventing beta-amyloid (Abeta)-induced neuronal damage and Abeta42 production. Eur J Neurosci 2006, 23:1711-1720.

\section{Figures}




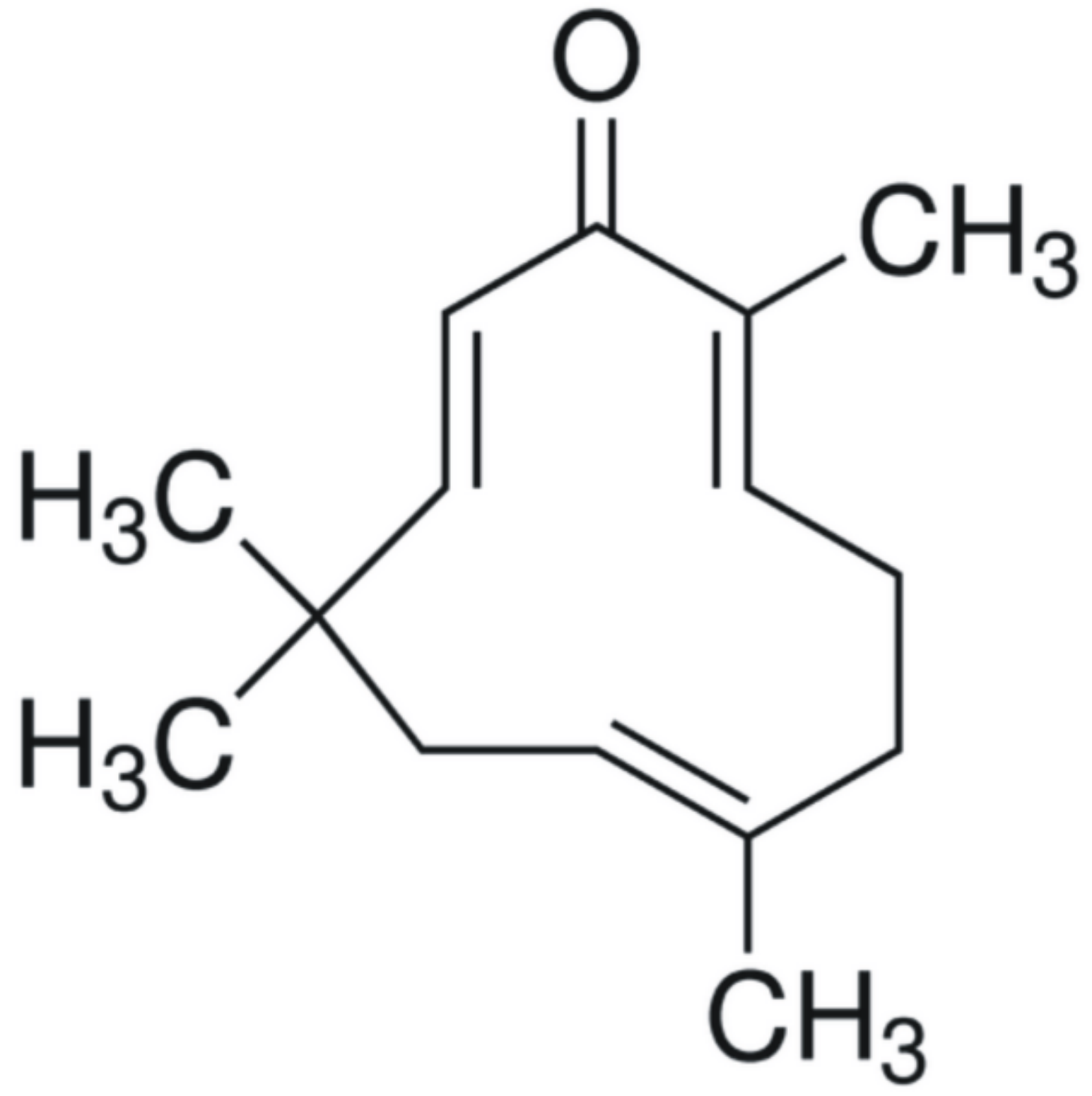

Figure 1

Molecular structure of zerumbone 

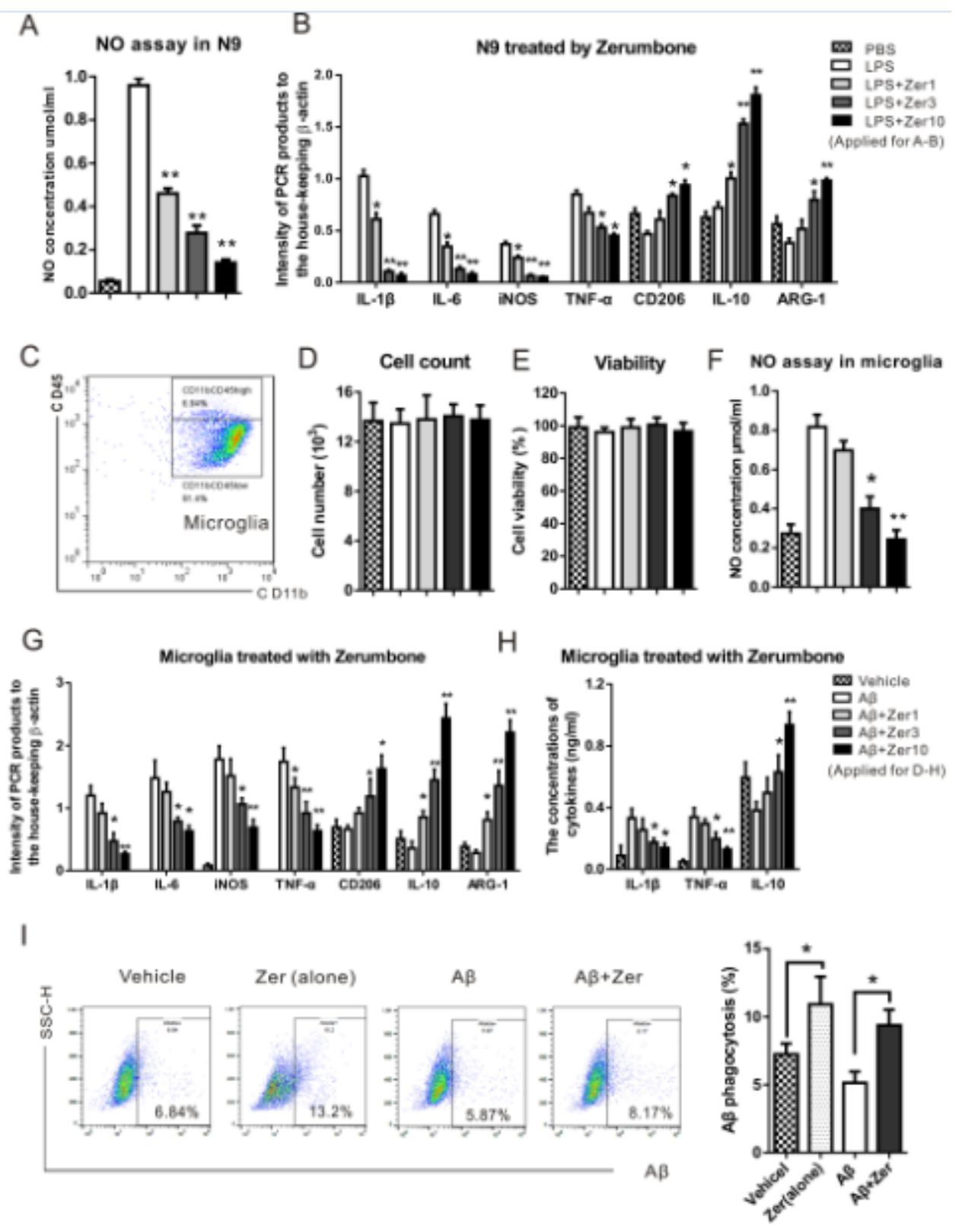

Figure 2

Zerumbone reduces inflammation and promotes the phenotypic conversion of microglia in vitro. The murine $\mathrm{N} 9$ microglial cell line and primary microglia isolated from newborn mice were stimulated with lipopolysaccharide $(1 \mu \mathrm{g} / \mathrm{ml})$ or $\beta$-amyloid $(A \beta ; 10 \mu \mathrm{M})$, and incubated with or without zerumbone $(1,3$ or $10 \mu \mathrm{g} / \mathrm{ml}$ ) for 24 hours. (A) Bar graph showing the nitric oxide (NO) concentration in N9 cells. Zerumbone treatment significantly reduced NO production. (B) Bar graph showing the expression levels of indicated genes including interleukin-1 $\beta$ (IL-1 $\beta$ ), interleukin-6 (IL-6), inducible nitric oxide synthase (iNOS), tumor necrosis factor-a (TNF-a), CD206, interleukin-10 (IL-10), and arginase-1 (ARG-1) in N9 cells. Zerumbone treatment significantly decreased the mRNA levels of IL-1 $\beta$, IL-6, iNOS, and TNF- $a$, and increased the mRNA levels of CD206, IL-10, and ARG-1 in a dose-dependent manner. (C) The purity of primary microglia was identified using flow cytometry, and CD11b+/CD45low cells were confirmed as microglia. (D, E) Cell Counting Kit-8 (CCK8) experiments showed that neither $A \beta$ nor different doses of zerumbone affected cell number or viability. (F) Bar graph showing the NO concentration in primary microglia cells. Zerumbone 
treatment significantly reduced NO production. (G) Bar graph showing the expression levels of indicated genes including IL-1 $\beta$, IL-6, iNOS, TNF-a, CD206, IL-10, and ARG-1 in primary microglia. Zerumbone treatment significantly decreased the mRNA levels of IL-1 $\beta$, IL-6, iNOS, and TNF- $a$, and increased the mRNA levels of CD206, IL-10, and ARG-1 in a dose-dependent manner. $(\mathrm{H})$ Bar graph showing the concentrations of cytokines (IL-1 $\beta$, TNF-a, and IL-10) in the cell culture supernatants of primary microglia. Zerumbone treatment significantly decreased the levels of IL-1 $\beta$ and TNF- $\alpha$, and increased the levels of IL10. (I) Fluorescence-activated cell sorting (FACS) results and a bar graph showing that zerumbone increased the phagocytosis of $A \beta$ in microglia cells.
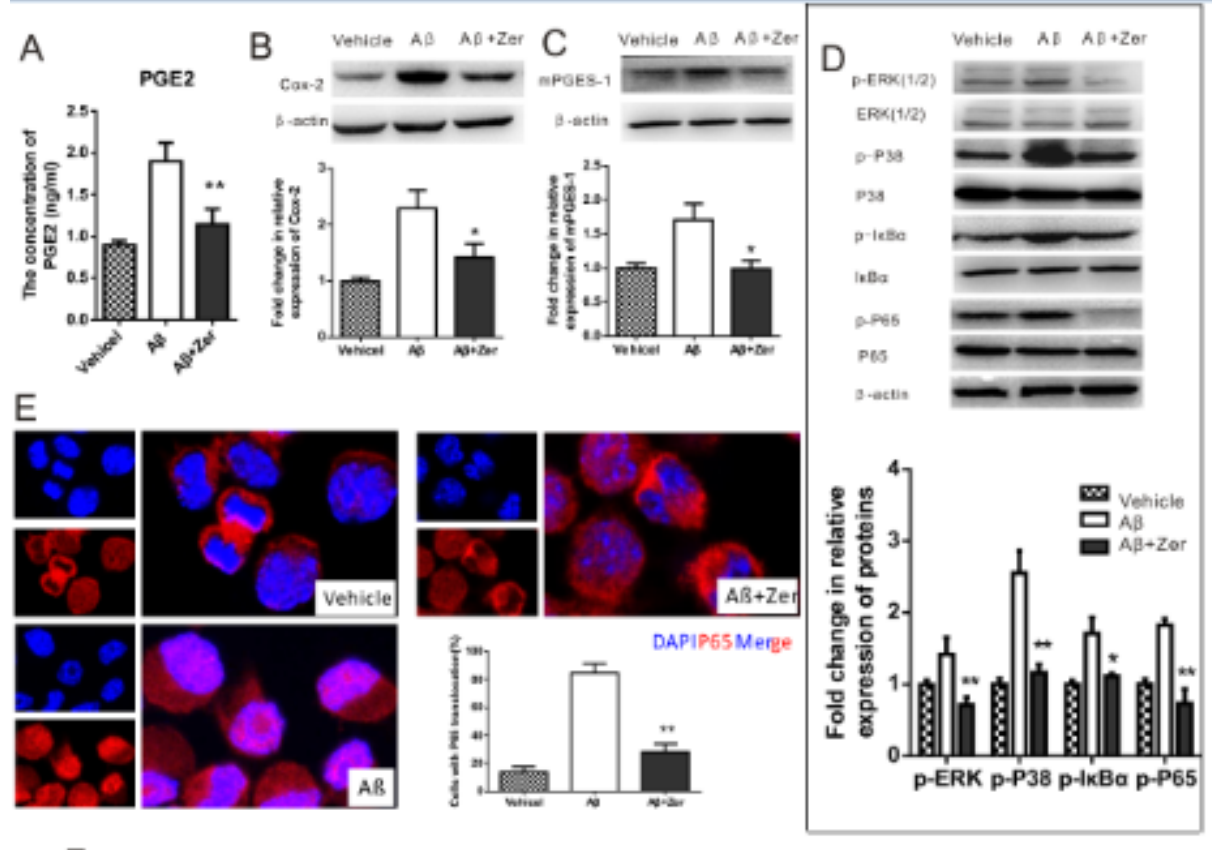

$\mathrm{F}$

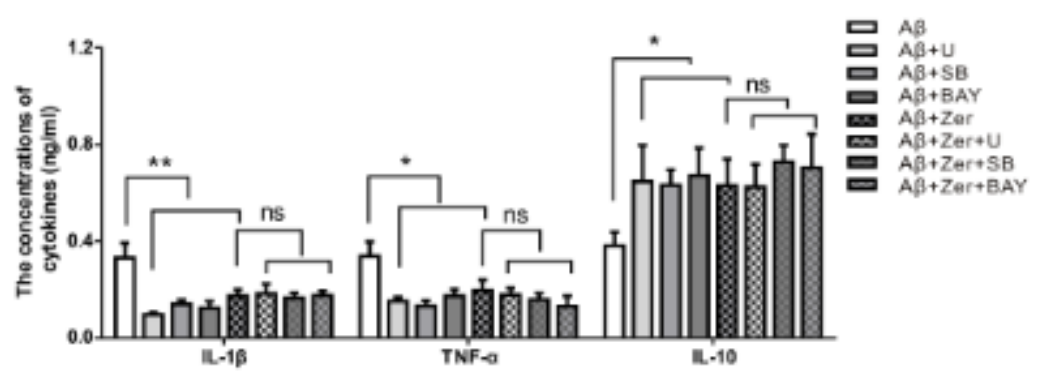

G

$\mathrm{H}$

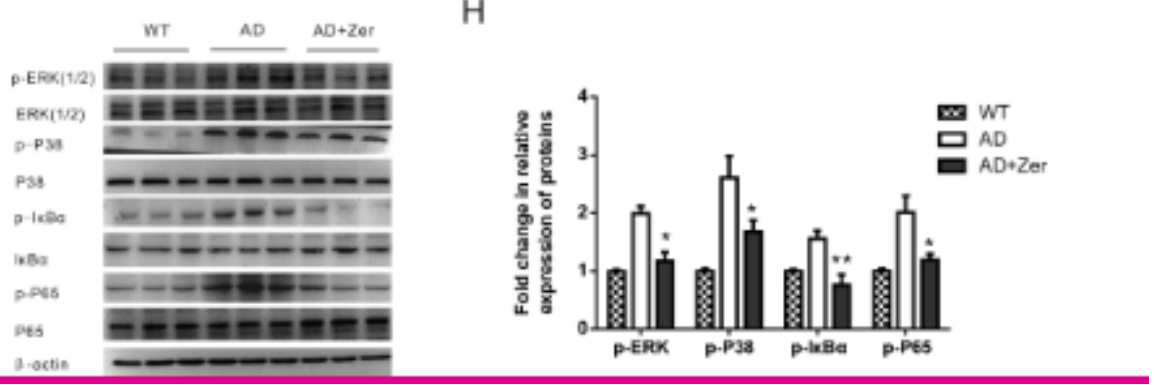

Figure 3

Zerumbone attenuates mitogen-activated protein kinase activation in microglial cells. (A) Bar graph showing the concentration of prostaglandin E2 (PGE2) in N9 cells. The production of PGE2 was significantly reduced by zerumbone. (B) Representative western blots and a bar graph showing the 
protein expression of cyclooxygenase-2 (Cox-2) in N9 cells. The production of Cox-2 was significantly reduced by zerumbone. (C) Representative western blots and a bar graph showing the protein expression of microsomal prostaglandin E synthase-1 (mPGES-1) in N9 cells. The production of mPGES-1 was significantly reduced by zerumbone. (D) Representative western blots and a bar graph showing the protein expression levels of $p$-extracellular signal-regulated kinase (p-ERK), ERK, p-p38, p38, p-ІкBa, IKBa, $p-p 65$, and p65 in $N 9$ cells. Zerumbone treatment significantly decreased the levels of $p$-ERK, $p-p 38, p-$ IKBa, and p-p65. (E) Zerumbone inhibited the translocation of nuclear factor-kappa B (NF-kB)from the cytosol to the nucleus in N9 cells treated with $A \beta$ for 24 hours. $(F)$ The concentrations of cytokines (interleukin-1 $\beta$ (IL-1 $\beta)$, tumor necrosis factor- a (TNF- $\alpha$ ), and interleukin-10 (IL-10)) in the cell culture supernatants of N9 microglia. Zerumbone, U0126, SB202190, and BAY 11-7082 blocked the A $\beta$ induced up-regulation of IL-1 $\beta$ and TNF-a production. The A $\beta$-induced decrease in IL-10 production was also reversed by zerumbone, U0126, SB202190, and BAY 11-7082. Data are presented as mean \pm SEM $(n=4)$. Zer1, 3, 10 = zerumbone concentrations of 1, 3, or $10 \mu \mathrm{g} / \mathrm{ml}$. U, U0126 (an ERK inhibitor); SB, SB202190 (a p38 inhibitor); BAY, BAY 11-7082 (an NF-KB inhibitor). (G, H) Primary microglia were isolated from the cortex of vehicle- and zerumbone-treated APP/PS1 mice. The microglia isolated from zerumbone-treated mice exhibited decreased protein levels of p-ERK1/2, p-p38, p-IKBa, and p-p65 compared to vehicle-treated mice. Data are presented as mean \pm SEM $(n=3) .{ }^{*} p<0.05$, ${ }^{*} p<0.01$.

A

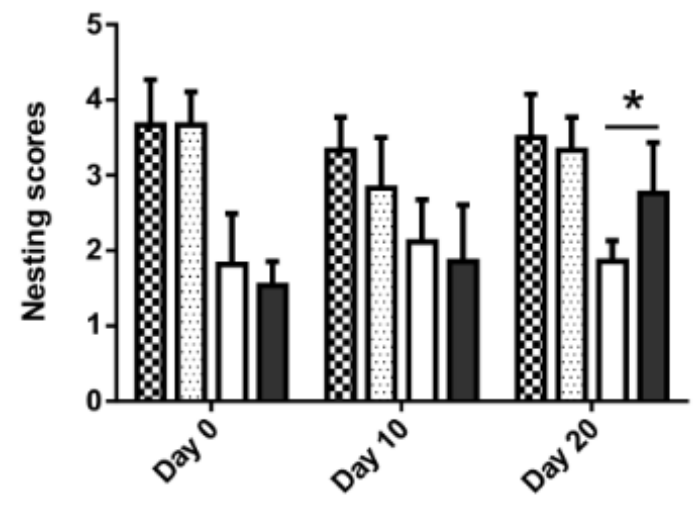

E

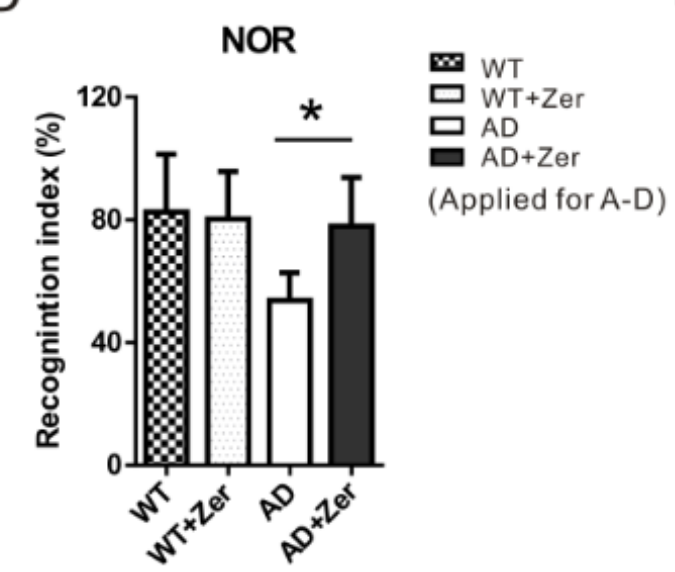

$\mathrm{B}$

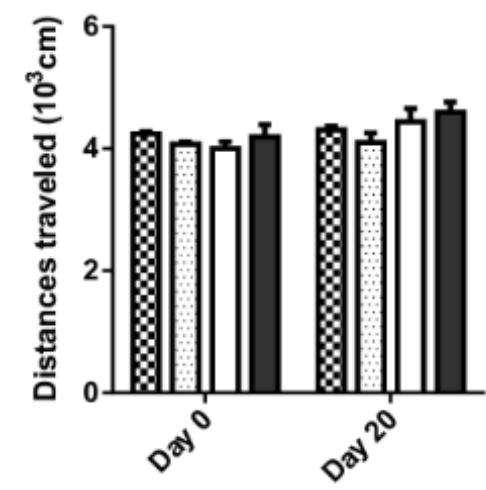

$B$ Distances traveled

Day 0

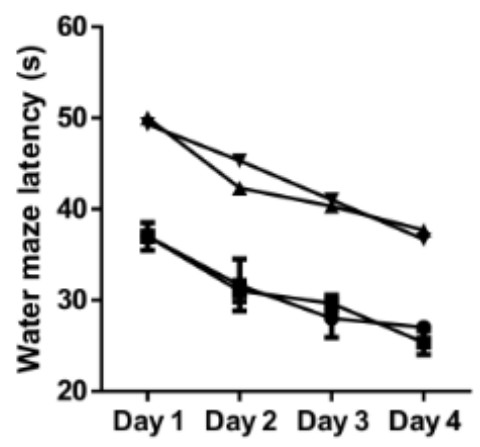

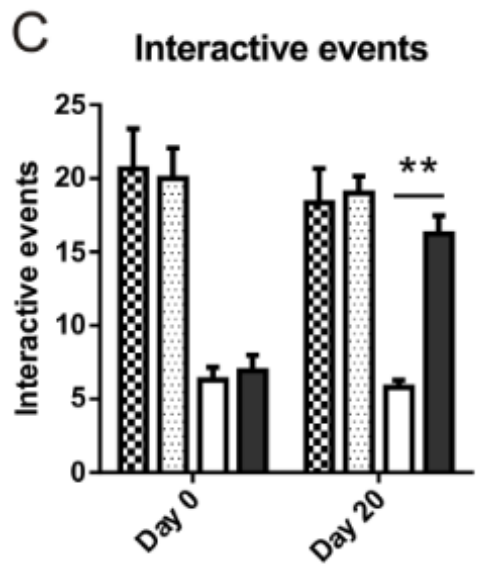

Day 20

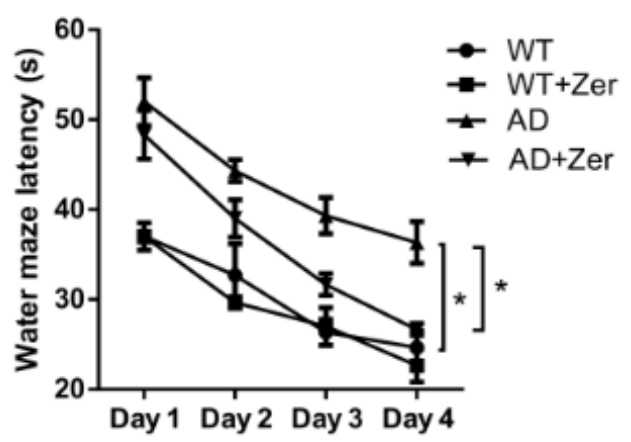

Figure 4 
Zerumbone alleviates behavioral impairments in APP/PS1 mice. APP/PS1 mice were treated for 20 days with zerumbone (or carboxymethylcellulose (CMC), vehicle) by gavage. (A) A nest construction assay was conducted involving a 3-point scale. The nest building scores at day 0 and day 10 were not significantly different between the vehicle- and zerumbone-treated APP/PS1 mice. At day 20, zerumbone-treated mice exhibited significantly higher nest building scores compared to vehicle-treated APP/PS1 mice. (B, C) A resident-intruder assay was conducted, and the distances traveled and numbers of interactive events were analyzed. Bar graph showing the distances traveled by vehicle- and zerumbone-treated APP/PS1 mice before and after zerumbone administration for 20 days. The vehicle- and zerumbone-treated mice did not exhibit significant differences in distances traveled at any time point (B). (C) Bar graph showing the number of interactive events of vehicle- and zerumbone-treated APP/PS1 mice before and after 20 days of treatment. At day 20, zerumbone-treated mice exhibited a significantly higher frequency of interactive behavior. (D) In the novel object recognition test, the length of time that the mouse spent exploring the novel object was recorded and the recognition index was calculated. The bar graph shows the recognition index of vehicle- or zerumbone-treated wild-type (WT) and APP/PS1 mice. At day 20, zerumbone significantly increased the recognition index of APP/PS1 mice. (E) Zerumbone ameliorated cognitive deficits in APP/PS1 mice in the hidden platform test of the Morris water maze test. All mice showed shorter escape latency on the fourth day, and APP/PS1 mice showed impaired cognitive function compared to WT mice. Zerumbone-treated APP/PS1 mice showed significant improvements in cognitive function during the 4 days of training compared to the vehicle-treated APP/PS1 mice. Data are presented as mean $\pm \operatorname{SEM}(n=7)$. ${ }^{*} p<0.05,{ }^{*} p<0.01$. 


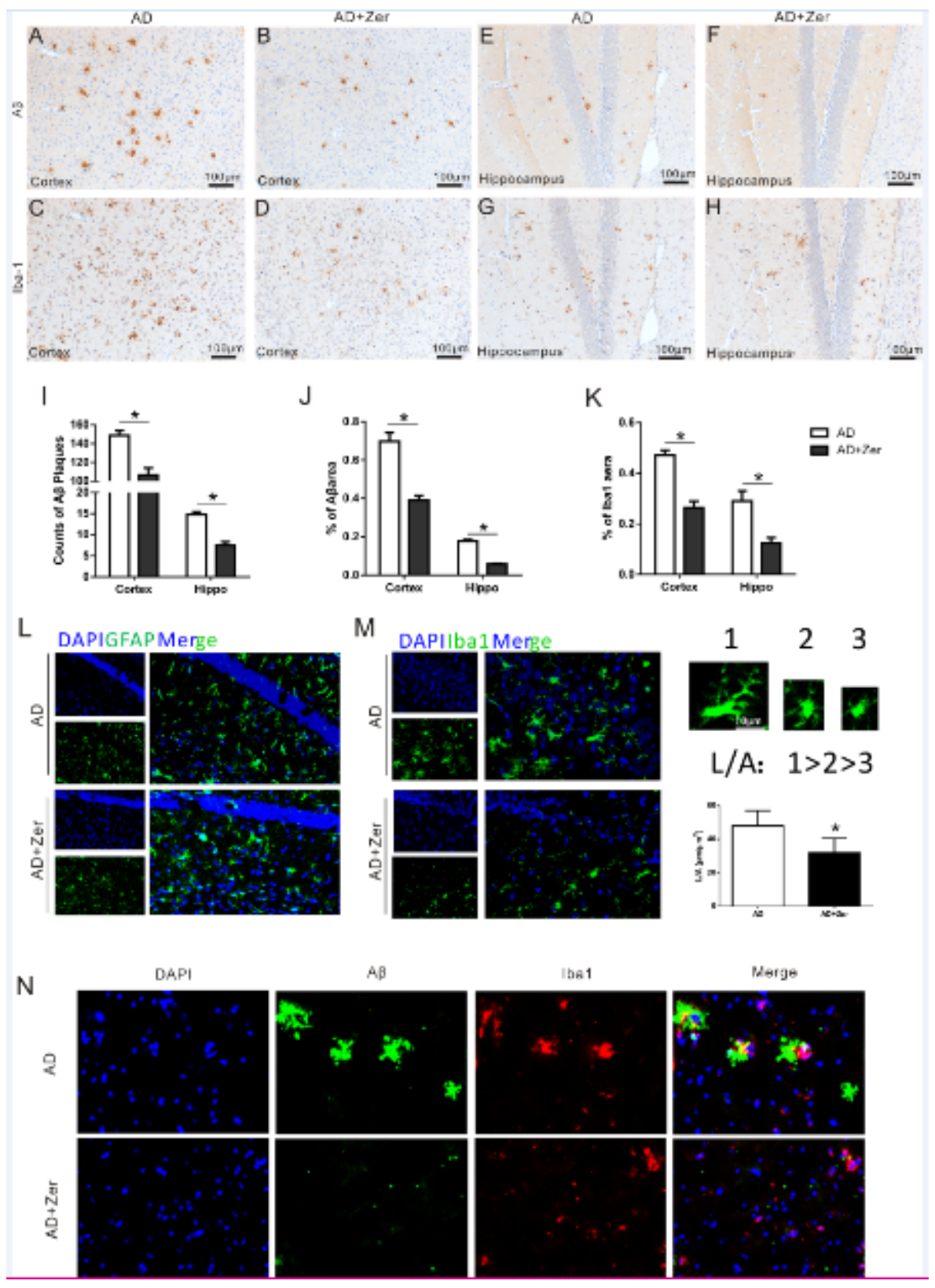

Figure 5

Zerumbone decreases $A \beta$ deposition and microglial activation in APP/PS1 mice. Five-month-old APP/PS1-21 mice, five males and two females, were treated for 20 days with zerumbone $(25 \mathrm{mg} / \mathrm{kg}$ by daily gavage). (A, $B, C, D)$ Representative photomicrographs of $\beta$-amyloid $(A \beta)$ immunohistochemical staining and ionized calcium-binding adaptor molecule 1 (Iba-1) immunohistochemical staining in the cortex of vehicle- and zerumbone-treated APP/PS1 mice. Zerumbone reduced A $\beta$ deposition and microglial activation in the cortex of APP/PS1 mice. $(E, F, G, H)$ Representative photomicrographs of $A \beta$ immunohistochemical staining and Iba-1 immunohistochemical staining in the hippocampus of vehicleand zerumbone-treated APP/PS1 mice. Zerumbone reduced $A \beta$ deposition and microglial activation in the hippocampus of APP/PS1 mice. Scale bar in $(A)-(H)=100 \mathrm{~mm}$. (I) Quantification of the numbers of $A \beta$ plaques in the cortex and hippocampus of APP/PS1 mice. $(\mathrm{J})$ Quantification of the percentage areas of the $A \beta$ staining in the cortex and hippocampus of APP/PS1 mice. (K) Quantification of the percentage 
areas of the lba-1 staining in the cortex and hippocampus of APP/PS1 mice. (L) Representative photomicrographs of glial fibrillary acidic protein (GFAP) immunofluorescence in the hippocampus of vehicle- and zerumbone-treated APP/PS1 mice. There were no significant differences between the groups. (M) Shape analyses of two-dimensional somatic projections based on maximum length $(\mathrm{L})$ and projection area $(A)$ in confocal images of Iba-1-immunostained microglia using ImageJ. The somatic shape index (L/A ratio) increases in rod-shaped somata. The $L, A$, and $L / A$ ratio of microglial somata were measured. $(N)$ Representative photomicrographs of $A \beta$ and Iba-1 double immunofluorescence in the cortex of vehicle- and zerumbone-treated APP/PS1 mice. Zerumbone treatment increased the phagocytosis of $A \beta$ by Iba- $1+$ microglia $(n=7)$. Data are presented as mean \pm SEM. ${ }^{\star} p<0.05$.

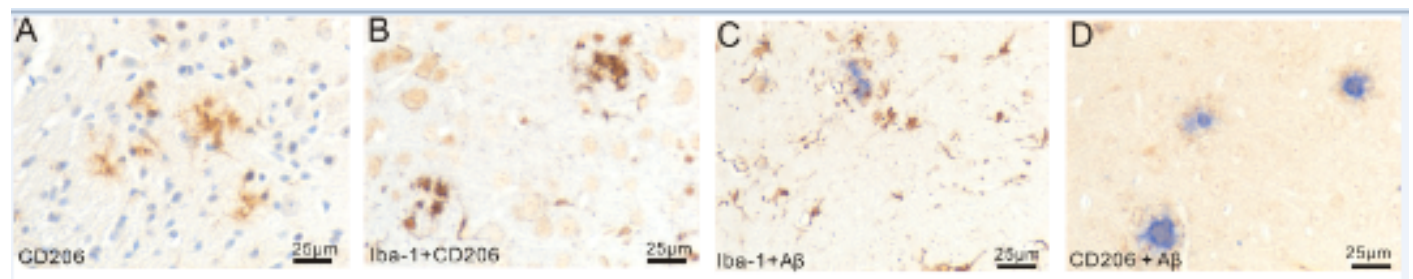

$\mathrm{E}$

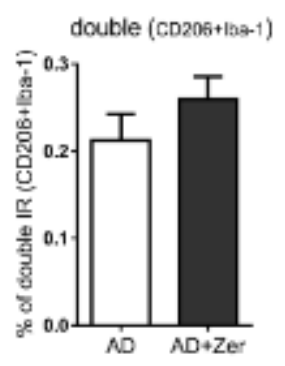

F

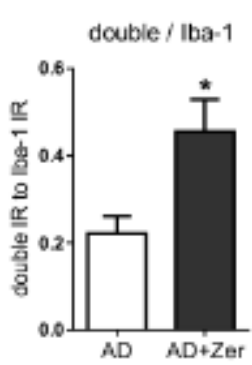

G

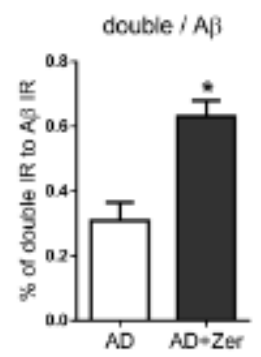

$\mathrm{H}$

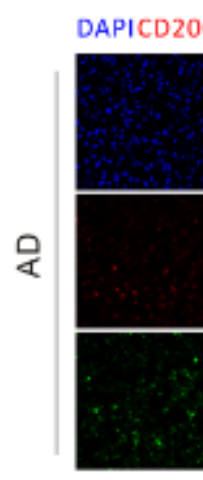

IbalMerge
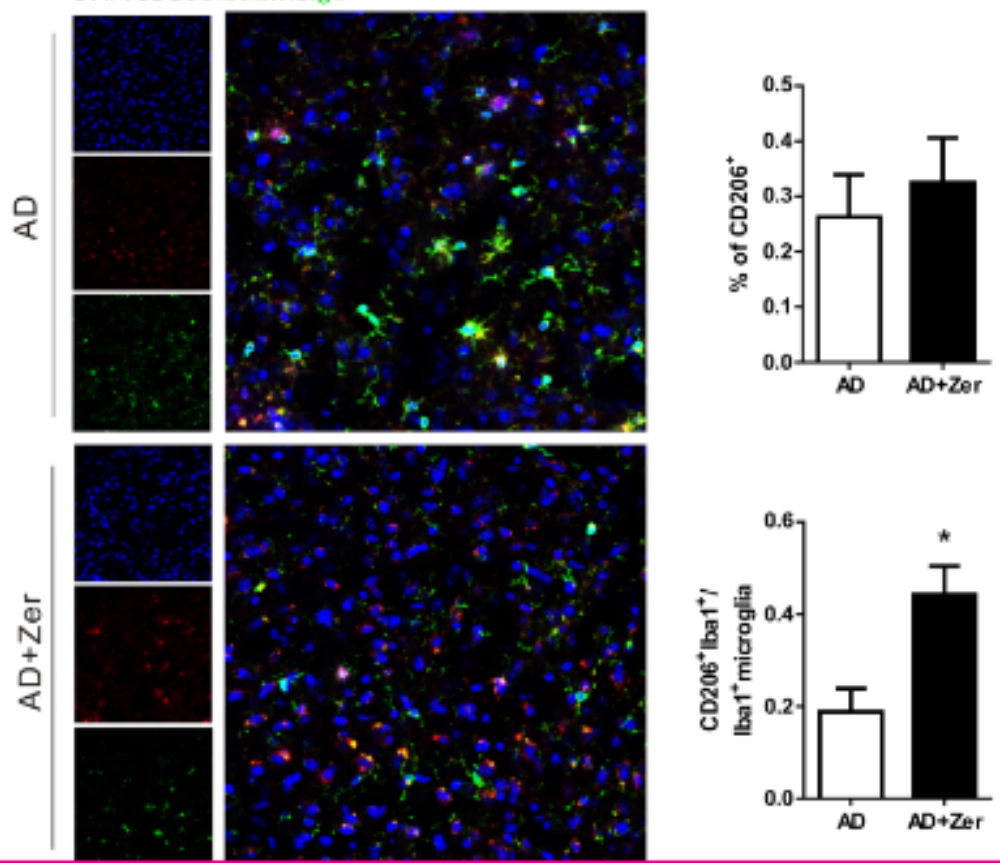

Figure 6

Zerumbone increases the expression of CD206 (an anti-inflammatory marker) in the cortex of APP/PS1 mice. Five-month-old APP/PS1-21 mice, five males and two females, were treated for 20 days with 
zerumbone ( $25 \mathrm{mg} / \mathrm{kg}$ by daily gavage). (A) Representative photomicrographs of CD206 immunohistochemical staining in the cortex of APP/PS1 mice. (B) Representative photomicrographs of CD206 and ionized calcium-binding adaptor molecule 1 (Iba-1) double immunohistochemical staining in the cortex of APP/PS1 mice. (C) Representative photomicrographs of lba- 1 and $\beta$-amyloid (A $\beta$ ) double immunohistochemical staining in the cortex of APP/PS1 mice. (D) Representative photomicrographs of CD206 and $A \beta$ double immunohistochemical staining in the cortex of APP/PS1 mice. (E) Quantification of the percentage of CD206 and Iba-1 in the cortex of vehicle- and zerumbone-treated APP/PS1 mice. The areas of CD206 IR and Iba- $1+C D 206$ double IR in the cortex were slightly increased by zerumbone treatment. (F) Quantification of the ratio of the area of Iba-1+CD206 double IR to the area of Iba- 1 IR in the cortex of vehicle- and zerumbone-treated APP/PS1 mice. The percentage of Iba- $1+C D 206$ double staining area to Iba-1 IR was significantly increased by zerumbone treatment. (G) Quantification of the ratio of the area of Iba- $1+C D 206$ double IR to the area of $A \beta I R$ in the cortex of vehicle and zerumbonetreated APP/PS1 mice. The ratio of the area of Iba- $1+C D 206$ double IR to the area of A IR was significantly increased by zerumbone treatment. $(H)$ Representative photomicrographs of CD206 and Iba1 immunofluorescence double staining in the cortex of APP/PS1 mice. The percentage areas of CD206 and the ratio of the area of Iba- $1+C D 206$ double IR to the area of Iba- 1 IR were determined $(n=7)$. ${ }^{*}<<$ 0.05 .

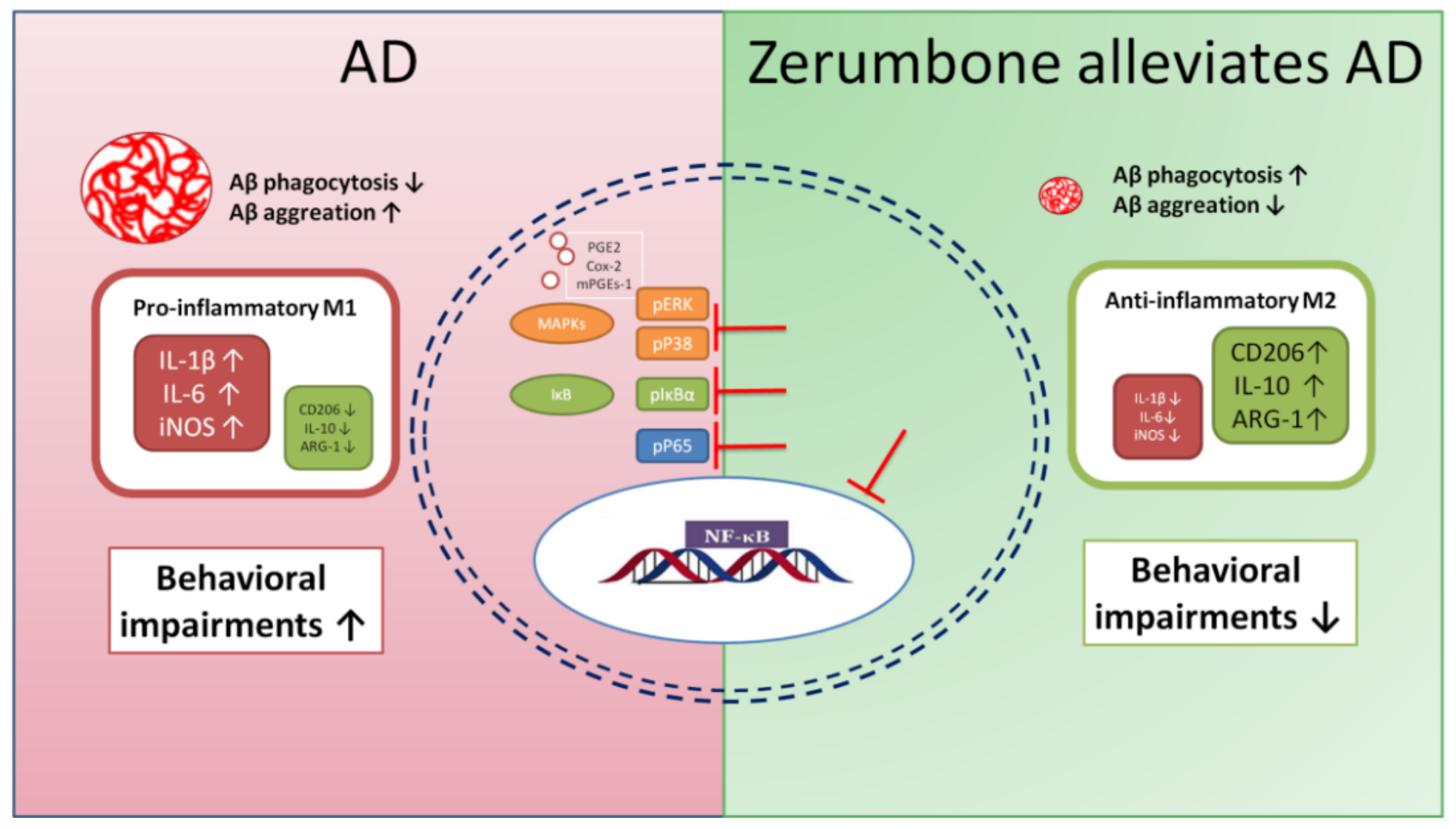

Figure 7

Schematic drawing depicting the suppression of MAPK signaling in microglia to alleviate AD by zerumbone. In the Alzheimer's disease (AD) brain, $\beta$-amyloid (AB) induces the release of interleukin- $1 \beta$ (IL$1 \beta$ ), interleukin-6 (IL-6), and inducible nitric oxide synthase (iNOS) and activates inflammatory microglia, 
suppressing $A \beta$ phagocytosis and promoting behavioral impairments (left, red). In this study, zerumbone inhibited the production of prostaglandin E2 (PGE2), cyclooxygenase-2 (Cox-2), and microsomal prostaglandin E synthase-1 (mPGEs-1). It also increased the proportion of anti-inflammatory microglia and ameliorated behavioral impairments and neuropathological changes in transgenic APP/PS1 mice by suppressing mitogen-activated protein kinase (MAPK) signaling (green). The inhibition of p-extracellular signal-related kinase ( $\mathrm{p}$-ERK), p-p38, and nuclear factor-kappa B (NF-KB) was a critical mechanism underlying the neuroprotective effect of zerumbone in microglia (right). 